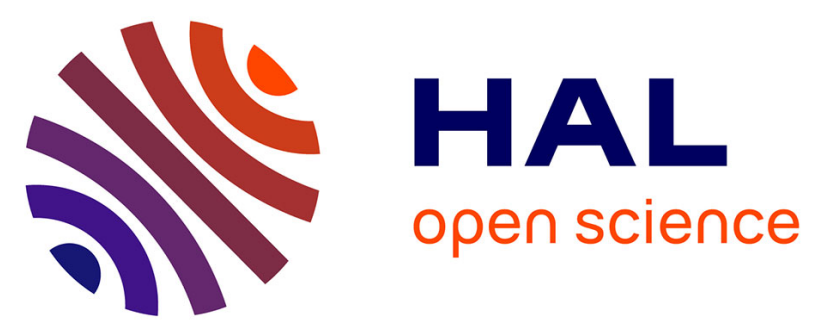

\title{
ANGPTL4 expression induced by butyrate and rosiglitazone in human intestinal epithelial cells utilizes independent pathways
}

Agata A. Korecka, Tomas T. de Wouters, Antonietta A. Cultrone, Nicolas N. Lapaque, Sven S. Pettersson, Joel J. Dore, Herve H. Blottiere, Velmurugesan V. Arulampalam

\section{To cite this version:}

Agata A. Korecka, Tomas T. de Wouters, Antonietta A. Cultrone, Nicolas N. Lapaque, Sven S. Pettersson, et al.. ANGPTL4 expression induced by butyrate and rosiglitazone in human intestinal epithelial cells utilizes independent pathways. AJP - Gastrointestinal and Liver Physiology, 2013, 304 (11), pp.G1025 - G1037. 10.1152/ajpgi.00293.2012 . hal-01001518

\section{HAL Id: hal-01001518 https://hal.science/hal-01001518}

Submitted on 28 May 2020

HAL is a multi-disciplinary open access archive for the deposit and dissemination of scientific research documents, whether they are published or not. The documents may come from teaching and research institutions in France or abroad, or from public or private research centers.
L'archive ouverte pluridisciplinaire HAL, est destinée au dépôt et à la diffusion de documents scientifiques de niveau recherche, publiés ou non, émanant des établissements d'enseignement et de recherche français ou étrangers, des laboratoires publics ou privés. 


\title{
ANGPTL4 expression induced by butyrate and rosiglitazone in human intestinal epithelial cells utilizes independent pathways
}

\author{
Agata Korecka, ${ }^{1 *}$ Tomas de Wouters, ${ }^{* 2,3}$ Antonietta Cultrone, ${ }^{2,3}$ Nicolas Lapaque, ${ }^{2,3}$ Sven Pettersson,,${ }^{1,4}$ \\ Joël Doré, ${ }^{2,3}$ Hervé M. Blottière, ${ }^{\Delta 2,3}$ and Velmurugesan Arulampalam ${ }^{\Delta 1}$ \\ ${ }^{1}$ Karolinska Institutet, Department of Microbiology, Tumor and Cell Biology (MTC), Stockholm, Sweden; ${ }^{2}$ INRA, UMR 13919 \\ Micalis, and ${ }^{3}$ AgroParisTech, UMR Micalis, Domaine de Vilvert, Jouy-en-Josas, France; ${ }^{4}$ Laboratory of Inflammation \\ Biology, Department of Cellular and Molecular Research, National Cancer Centre Singapore, Singapore
}

Submitted 12 July 2012; accepted in final form 19 March 2013

\begin{abstract}
Korecka A, de Wouters T, Cultrone A, Lapaque N, Pettersson S, Doré J, Blottière HM, Arulampalam V. ANGPTL4 expression induced by butyrate and rosiglitazone in human intestinal epithelial cells utilizes independent pathways. Am J Physiol Gastrointest Liver Physiol 304: G1025-G1037, 2013. First published March 21, 2013; doi:10.1152/ajpgi.00293.2012.- Short-chain fatty acids (SCFAs), such as butyrate and propionate, are metabolic products of carbohydrate fermentation by the microbiota and constitute the main source of energy for host colonocytes. SCFAs are also important for gastrointestinal health, immunity, and host metabolism. Intestinally produced angiopoietin-like protein 4 (ANGPTL4) is a secreted protein with metabolism-altering properties and may offer a route by which microbiota can regulate host metabolism. Peroxisome proliferator-activated receptor (PPAR)- $\gamma$ has previously been shown to be involved in microbiota-induced expression of intestinal ANGPTL4, but the role of bacterial metabolites in this process has remained elusive. Here, we show that the SCFA butyrate regulates intestinal ANGPTL4 expression in a PPAR- $\gamma$-independent manner. Although PPAR- $\gamma$ is not required for butyrate-driven intestinal ANGPTL4 expression, costimulating with PPAR- $\gamma$ ligands and SCFAs leads to additive increases in ANGPTL4 levels. We suggest that PPAR- $\gamma$ and butyrate rely on two separate regulatory sites, a PPAR-responsive element downstream the transcription start site and a butyrate-responsive element(s) within the promoter region, $0.5 \mathrm{~kb}$ upstream of the transcription start site. Furthermore, butyrate gavage and colonization with Clostridium tyrobutyricum, a SCFA producer, can independently induce expression of intestinal ANGPTL4 in germ-free mice. Thus, oral administration of SCFA or use of SCFA-producing bacteria may be additional routes to maintain intestinal ANGPTL4 levels for preventive nutrition or therapeutic purposes.
\end{abstract}

short-chain fatty acids; peroxisome proliferator-activated receptor- $\gamma$; fasting-induced adipose factor; angiopoietin-like protein 4; Clostridium tyrobutyricum

THE HUMAN GASTROINTESTINAL (GI) tract has long been perceived as an organ with purely digestive functions. This perception has radically changed over the last decades as it emerged that the function of the GI tract is not only limited to energy uptake but also affects regulatory processes with wide-ranging systemic effects. These are either directly related to its digestive functions or independent ones impacting on local and systemic inflammation (reviewed in Ref. 50), metabolism (reviewed in Ref. 41), and even behavior $(8,10,24)$. Intestinal epithelial cells (IECs) represent the first line of contact between the host

*A. Korecka and T. de Wouters contributed equally to this work. ${ }^{\Delta} \mathrm{H}$. Blottière and V. Arulampalam contributed equally to this work.

Address for reprint requests and other correspondence: H. M. Blottière, INRA, UMR 1319 MICALIS, Bat 405, Domaine de Vilvert, F-78352 Jouyen-Josas, France (e-mail: herve.blottiere@ jouy.inra.fr). and the intestinal microbiota. This monolayer of cells covered by mucus has important barrier functions preventing the attachment and invasion of intestinal bacteria, while supporting the coexistence of the intestinal microbiota with its host (43). This crosstalk contributes among other things to the physiological state of the IEC including maturation and the integrity of the overall epithelial barrier (53). The importance of a well-regulated response to the intestinal microbiota and its metabolites has repeatedly been shown to be crucial to the health of the host (reviewed in Refs. 12 and 31).

Mouse studies have also linked intestinal colonization to the capacity of energy utilization and weight gain $(5,6)$. One mechanism implied in this process is the regulation of angiopoietin-like protein 4 (ANGPTL4) expression in the intestinal epithelium. ANGPTL4 is a secreted protein with a variety of functions ranging from regulation of lipid and glucose homeostasis to inhibition of cell migration and angiogenesis (reviewed in Ref. 21). The $\mathrm{NH}_{2}$-terminal domain of ANGPTL4 inhibits lipoprotein lipase (LPL) activity and hence diminishes the capacity of triglyceride uptake and storage by diverse tissues, including adipocytes (20), where it additionally induces lipolysis $(33,39)$, resulting in the elevation of circulating triglyceride levels. In human studies, diabetes has been associated with decreased serum-levels of ANGPTL4 (55), and obesity has been shown to inversely correlate with serum ANGPTL4 (44). The functional role of ANGPTL4 within the gastrointestinal tract remains obscure. Deletion of ANGPTL4 results in profound metabolic changes, decreased intestinal absorption of oils, thickening of the intestinal mucosa, and infiltration of foamy macrophages to the lamina propria (16). The latter observation is of particular interest because another report contends that ANGPTL4 protects against fatty acid-induced inflammation by blocking lipid uptake in macrophages (34). Animal and in vitro studies showed that intestinal ANGPTL4 expression can be strongly influenced by the microbiota (3-5), leading to modulations of lipid storage and body mass.

These findings raise the question as to how microbiota regulate ANGPTL4 expression in IEC. One of the postulated mechanisms of action is via ligand-activated transcription factors, such as members of the peroxisome proliferator-activated receptor (PPAR) family. In the intestinal epithelium, PPAR- $\gamma$ is the most studied PPAR isoform, and it is implicated in the regulation of fatty acid metabolism via $\beta$-oxidation and in cell proliferation (54), as well as in gut homeostasis (1, 40). PPAR- $\gamma$ regulates ANGPTL4 expression $(3,29)$, and a PPARresponsive element (PPRE) within the third intron of the ANGPTL4 gene in humans and mice was identified $(28,38)$. Furthermore, in zebrafish, intron 3 of the ANGPTL4 locus is 
sufficient to drive expression of ANGPTL4 in the liver, pancreatic $\beta$-cells, and intestinal enterocytes (11). PPAR- $\gamma$ is activated by many synthetic and natural ligands, and shortchain fatty acids (SCFAs) have been purported to be one such activator $(2,30)$. SCFAs are products of bacterial fermentation of dietary fiber (reviewed in Refs. 23 and 47) and are the main energy source for colonocytes $(18,19,45)$. SCFAs, especially propionate and butyrate, are also potent inhibitors of histone deacetylation $(9,48,51)$, although the exact mechanism behind this effect is not known (reviewed in Ref. 14). Levels of and proportions between the amounts of the three main SCFAs, acetate, propionate, and butyrate, not only vary between individuals and diets but also depend on the intestinal compartment (reviewed in Ref. 52). In adult humans fecal butyrate content lies between $10-20 \mathrm{mM}$, whereas in mice butyrate concentrations of $3.5,0.8$, and $0.5 \mathrm{mM}$ were detected in the proximal, medial, and distal colonic segments, respectively (17). In mice, SCFA concentrations of below $10 \mathrm{mM}$ in the proximal small intestine to more than $40 \mathrm{mM}$ in the cecum and colon were described (2). Additionally, that study also provides data showing that acetate is the predominant SCFA, followed by propionate and butyrate. In our in vitro experiments, we have used decreasing concentrations of these three SCFAs (acetate $>$ propionate $>$ butyrate) mimicking their physiological abundance and availability.

Clostridium tyrobutyricum (DSM 2637, C. tyrobutyricum) is one of many bacterial species able to synthesize SCFAs from dietary fibers (36). C. tyrobutyricum is a Gram-positive, rod-shaped, spore-forming anaerobic bacterium isolated from cow milk, with the ability to ferment a wide variety of dietary carbohydrates to butyric acid, without producing cytotoxins (46).

In the present study, we focused on the impact of SCFAs and the role of PPAR- $\gamma$ in intestinal ANGPTL4 expression. Here, we show that ANGPTL4 expression can be regulated by SCFAs both in vitro and in vivo, with butyrate being the most efficient activator. This butyrate-driven effect is independent of PPAR- $\gamma$ and can be attributed to a promoter element, lacking any PPRE, $0.5 \mathrm{~kb}$ upstream of the transcriptional start site of ANGPTL4.

\section{MATERIALS AND METHODS}

Reagents and cell culture. The human epithelial cell lines, HT-29, HCT-116, Caco-2, and SW-1116 were obtained from the American Type Culture Collection (ATCC). INT-407 cell line was a generous gift from Anita Sjölander, Lund University, Lund, Sweden. The cells were grown in RPMI 1640 (HT-29, SW-1116), DMEM (Caco-2), BME (INT-407), or McCoy (HCT-116) media supplemented with $2 \mathrm{mM}$ L-glutamine, $50 \mathrm{IU} / \mathrm{ml}$ penicillin, $50 \mu \mathrm{g} / \mathrm{ml}$ streptomycin, and $10 \%$ (15\% for INT-407 and 20\% in the case of Caco-2) heat-inactivated fetal calf serum. Cells were maintained in a $37^{\circ} \mathrm{C}$ humidified atmosphere of $5 \% \mathrm{CO}_{2}$ (10\% for Caco-2). Cell culture media for HT-29, INT-407, and HCT-116 were purchased from Invitrogen and cell culture reagents from Sigma Aldrich. Cell culture media and reagents for SW-1116 and Caco-2 cells were all from Lonza. Epithelial morphogenesis of each cell line was monitored microscopically, and cell densities for each experiment did not exceed $80 \%$ to prevent contact inhibition.

$R N A$ extraction and $R T-q P C R$. For mRNA analyses, cells were plated in a 24 -well plate at the density of $2.5 \times 10^{5}$ cells $/ \mathrm{cm}^{2}\left(1.25 \times 10^{5}\right.$ cells $/ \mathrm{cm}^{2}$ for Caco- 2 cell line) in culture medium. For stimulation of cells, the following reagents were used: DMSO, sodium butyrate, sodium propionate, sodium acetate, trichostatin A (all from Sigma Aldrich), rosiglitazone, and GW9662 (Cayman Chemicals). Inhibition experiments using PPAR- $\gamma$ inhibitor GW9662 $(10 \mu \mathrm{M})$ were performed by pretreating cells with the inhibitor or vehicle (DMSO) for $1 \mathrm{~h}$ before applying the indicated stimulation. RNA was isolated using Qiagen RNeasy Mini-kit according to manufacturer's instructions. cDNA was synthesized with Super-Script II (Invitrogen). Oligo-dT primers were used in the presence of RNaseOUT reagent (Invitrogen). A sample (1 $\mu \mathrm{g})$ of RNA was used per reaction. cDNA was diluted 1:5, and $1 \mu \mathrm{l}$ was further used for qPCR reaction. qPCRs were performed using Sybr-Green reagent (Applied Biosystems) and gene-specific primers [adipose differentiation-related protein (ADRP): Frw 5'-CTGTTCACCTGATTGAATTTGC-3' and Rev 5'-AGAGCTTATCCTGAGCATCCTG-3'; ANGPTL3: Frw 5'TTCAATGAAACGTGGGAGAA-3' and Rev 5'-TCTTCTCTAGGCCCAACCAA-3'; ANGPTL4: Frw 5' -AAAGAGGCTGCCCGAGAT-3' and Rev 5'-TCTCCCCAACCTGGAACA-3'; $\beta$-actin: Frw 5'CCTGGCACCCAGCACAAT-3' and Rev 5'-GCCGATCCACACGGAGTACT-3'; p21: Frw 5'-GACTCTCAGGGTCGAAAACG-3' and Rev $5^{\prime}$-GGCGTTTGGAGTGGTAGAAA-3', fatty acid-binding protein gene 1 (FABP1): Frw 5'-TCACCGCTGGGTCCAAA-3' and Rev 5' CATTGTCTCCAGCTCACATTCC-3'; Keratin 20: Frw 5'-CTGAATAAAGACCTAGCTCTCCTCAAA-3' and Rev 5'-TGTTGCCCAGATGCTTGTGT-3'; PPAR- $\gamma 1$ : Frw 5'-AAGGCCATTTTCTCAAACGA-3' and Rev 5'-ACGGAGCTGATCCCAAAGTT-3']; mouse ANGPLT4: Frw 5'-CAACGCCACCCACTTACA-3' and Rev 5'-CAGAGGCTGGATCTGGAAAA-3'; mouse $\beta$-actin: Frw 5' CTGTATTCCCCTCCATCGTG-3' and Rev 5'-CCTCGTCACCCACATAGGAG-3' . Reactions were performed in Abi Prism 7500 (Applied Biosystems) thermal cycler. $\beta$-Actin expression did not show significant differences between treatments and was used as a housekeeping gene. Relative expression was calculated using the formula $2^{-\Delta \Delta \mathrm{Ct}}$. Average from the controls was taken as 1 , and fold change for each treatment was calculated accordingly. Each sample was measured in duplicates. Each experiment was performed in triplicate, and representative results for at least three different experiments are shown.

Western blot. After treatment, cells were lysed in Schindler lysis buffer [50 mM Tris pH 8, 0.1 mMEDTA, 0.5\% NP-40, 10\% Glycerol, $150 \mathrm{mM} \mathrm{NaCl}, 10 \mathrm{nM}$ okadaic acid, $5 \mathrm{mM}$ sodium fluoride, $400 \mathrm{mM}$ sodium vanadate, $1 \times$ Complete Protease Inhibitors (Roche); $1 \mathrm{mM}$ phenylmethanesulphonylfluoride]. The PPAR- $\gamma$ antibody (Santa Cruz) was used at a 1:1,000 dilution, while immunodetection was carried out by an anti-mouse secondary peroxidase-conjugated antibody (DAKO A/S) followed by chemiluminescence detection (BioRad). GAPDH primary antibody conjugated with horseradish peroxidase (Sigma Aldrich) was used for loading control.

ELISA. Cells were plated in a 24-well plate as described above. Culture medium was replaced with a fresh one before stimulation to ensure that only ANGPTL4 secreted after stimulation was measured. Cell culture medium was collected either 6 or $24 \mathrm{~h}$ following stimulation with acetate $(10 \mathrm{mM})$, propionate $(5 \mathrm{mM})$, butyrate $(2 \mathrm{mM})$, trichostatin A (TSA) $(500 \mathrm{nM})$, rosiglitazone $(5 \mu \mathrm{M})$, or a combination of rosiglitazone and butyrate. $0.025 \%$ DMSO was used as control. Cell culture medium was centrifuged at 14,000 revolution/min for 7 min, and $100 \mu \mathrm{l}$ of supernatant was applied directly on anti-ANGPTL4 precoated ELISA plates (Biosite). ELISA was performed according to manufacturer's instructions. Each sample was measured twice, and the experiments were performed in quadruplicate.

siRNA. HT-29 cells were plated at a density of $0.625 \times 10^{5} / \mathrm{cm}^{2}$. Downregulation of PPAR- $\gamma$ transcripts in HT-29 cells was achieved by Silencer Select siRNA products directed against PPAR- $\gamma$ (Ambion). Controls were transfected with Silencer Select Negative Control 2 siRNA (Ambion). Transfection was carried out according to manufacturer's protocol using DharmaFECT 4 (Thermo Scientific) reagent (final concentration of $0.3 \%$ ) with a final siRNA concentration of $40 \mathrm{nM}$. Twenty-four hours after transfection, cells were treated with rosiglitazone $(5 \mu \mathrm{M})$ or butyrate $(2 \mathrm{mM})$. Control was treated with $0.1 \%$ DMSO. ANGPTL4 and PPAR- $\gamma$ expression was measured 
by $\mathrm{qPCR}$ as described above. There was no significant difference in the efficacy of PPAR- $\gamma$ knockdown between treatments. Each sample was measured twice, and the experiment was performed in triplicate.

Plasmid construction. The luciferase reporter gene was cloned into the $\mathrm{KpnI} / \mathrm{XbaI}$ sites of the pCDNA3.1/Zeo(+) vector (Invitrogen). pCMV promoter was removed through NruI/NheI digestion. Three different fragments of the ANGPTL4 promoter region directly upstream of the transcriptional start were amplified from human genomic DNA by PCR using the High Fidelity PCR Mix (Fermentas) using the following primers: FF1.8 Frw: TTTTTTGCTAGCCTCAGGACATTAAAGACCCTGGCGGTAGAG; FF1.2 Frw: TTTTGCTAGCTAGAGGGTAGGCTATGGGGG; FF0.5 Frw: TTTTGCTAGCCCTCTCCGCCACTGGGTAAG, FF1 Rev: TTTTTTGGTACCCCTCTTAGGTAGCCTGGGAGCGGGGATTCG, and it was cloned as a NheI/KpnI fragment in pCDNA3.1-Luc plasmid. The resulting plasmids are referred to as pANGPTL4-1.8-luc, pANGPTL4-1.2-luc, and pANGPTL4-0.5luc, respectively.

Transient transfection assays. For transient transfection assays, $2.5 \times$ $10^{5}$ cells were seeded per well and transfected using Lipofectamine 2000 reagent (Invitrogen) following the manufacturer's instructions. All reporter constructs expressed firefly luciferase under different ANGPTL4 promoter fragments in pcDNA3.1 depleted of its CMV promoter as a vector (as described above). All samples were cotransfected with pGL4.79 (Promega) carrying a Renilla luciferase under control of a CMV promoter (negative control). Signal was quantified using DualGlo Luciferase Assay System (Promega). The firefly luciferase signal was normalized toward the Renilla luciferase signal and expressed as a fold increase.

Stable transfection and luciferase assay. The stable SW-1116 pANGPTL4-1.8-luc reporter clone was obtained by transfecting SW1116 cells with the pANGPTL4-1.8-luc construct using the Nucleofector (Amaxa) following the manufacturer's instructions. Cells were cultured for 3 wk under Zeocine selection $(50 \mu \mathrm{g} / \mathrm{ml}$, Invitrogen $)$. Clones were selected for their response to $2 \mathrm{mM}$ sodium butyrate (Sigma) after 24-h stimulation. Luciferase activity, quantified as relative luminescence units (RLU), was measured using the ONEGlo Luciferase Assay System (Promega) according to the manufacturer's instructions using a microplate reader (Infinite 200, Tecan).

Animal experiments. Ten- to -twelve-week-old male germ-free (GF) NMRI and C57Bl/6J mice as well as specific pathogen-free (SPF) C57B1/6J were maintained on autoclaved R36 Lactamin chow (Lactamin) while kept in 12-h light cycle.

GF NMRI mice were divided in two groups; one was gavaged with sterile water, whereas the other received sodium butyrate $(1 \mathrm{~g} / \mathrm{kg}$ body wt). Oral gavage was performed twice for each mouse at 24 and $6 \mathrm{~h}$ before sample collection. Mice were killed by cervical dislocation.

C. tyrobutyricum (DSM 2637), a generous gift from Tomas Hudcovic (Department of Immunology and Gnotobiology - Institute of Microbiology - Praha, The Czech Republic), was cultured in Bryant Burkey Bouillon with Resazurin (Merck), and $1 \times 10^{8}$ bacteria were used to colonize each $\mathrm{C} 57 \mathrm{Bl} / 6 \mathrm{~J}$ GF mouse. Colonized mice were killed by cervical dislocation along with age-matched GF and SPF mice. For each animal sample, fetal material was collected, and the presence of $C$. tyrobutyricum was confirmed using a PCR-based method.

All protocols involving animals were approved by the Regional Animal Research Ethical Board, Stockholm, Sweden (Stockholms norra djurförsöksetiska nämnd), following proceedings described in EU legislation (Council Directive 86/609/EEC). Animal husbandry was in accordance with institutional guidelines at Karolinska Institutet and was approved by the above mentioned ethical board (Ref: N 100/10).

Statistical analysis. Student's $t$-test, one-way ANOVA (with Tukey's post hoc correction) and two-way ANOVA (with Bonferroni correction) statistical analyses were performed using GraphPad version 4.0. Welch's correction after Student's $t$-test was applied for comparison of data with unequal variances.

\section{RESULTS}

Induction of ANGPTL4 expression by butyrate. To study the effect of butyrate on the regulation of ANGPTL4 expression in the human intestine, ANGPTL4 mRNA expression levels were quantified by real-time qPCR in three different IEC lines, namely HT-29, INT-407, and HCT-116. Cells were stimulated for $6 \mathrm{~h}$ with either butyrate or rosiglitazone, the latter being a selective PPAR- $\gamma$ activator known to induce expression of ANGPTL4 in IECs (3). All three cell lines showed an upregulation of ANGPTL4 transcription upon stimulation with butyrate, albeit with different levels of response (Fig. 1). The reason behind different magnitudes of responses to stimulation is not known but might partially be explained by the difference in basal level of ANGPTL4 transcription in unstimulated cells. HT-29 cells show relatively low levels of ANGPTL4 when untreated, followed by INT-407, whereas HCT-116 show the highest basal expression level of this gene (A. Korecka and V.
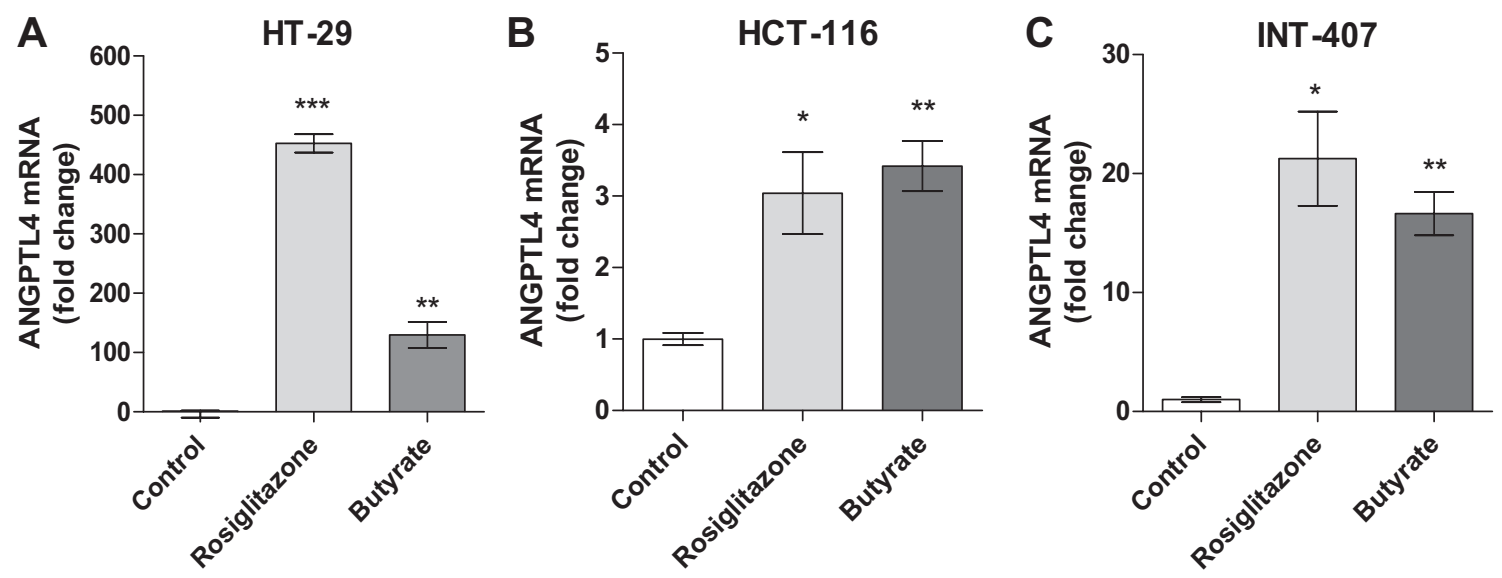

Fig. 1. Butyrate treatment increases expression of angiopoietin-like protein 4 (ANGPTL4) in various intestinal cell lines. Quantitative RT-PCR results showing effects of rosiglitazone $(5 \mu \mathrm{M})$ or butyrate $(2 \mathrm{mM})$ on ANGPTL4 mRNA in HT-29 $(A)$, HCT-116 $(B)$, and INT-407 $(C)$ cells $6 \mathrm{~h}$ after treatment. The control was treated with $0.025 \%$ DMSO. ANGPTL4 expression was normalized to $\beta$-actin. Student's $t$-test $* P<0.05$; $* * P<0.01 ; * * * P<0.001$ against the control. Bars and error bars show means $\pm \mathrm{SD}$. 

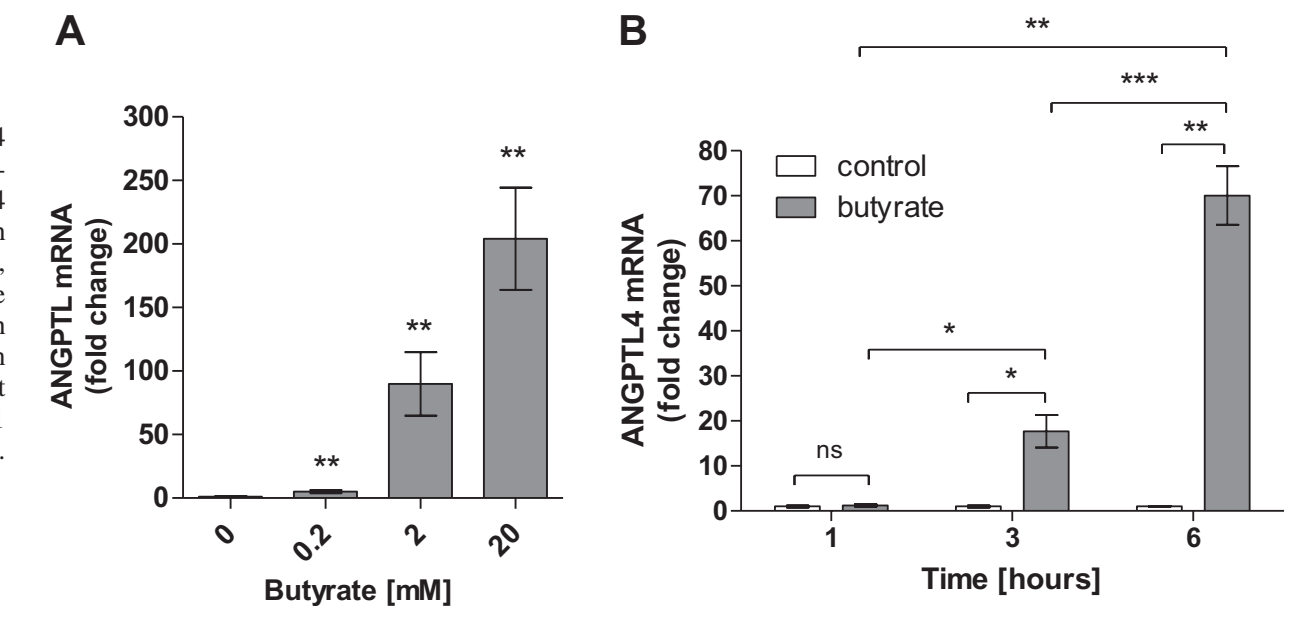

Fig. 2. The effect of butyrate on ANGPTL4 expression is dose and time dependent. Quantitative RT-PCR results showing ANGPTL4 expression in HT-29 cells after treatment with increasing doses of butyrate $(0.2 \mathrm{mM}, 2 \mathrm{mM}$, $20 \mathrm{mM}$ ) for $6 \mathrm{~h}(A)$ or $2 \mathrm{mM}$ sodium butyrate for 1,3 , or $6 \mathrm{~h}(B)$. Controls were treated with culture medium only. ANGPTL4 expression was normalized to $\beta$-actin. Student's $t$-test $* P<0.05 ; * * P<0.01 ; * * * P<0.001$ against the control or between indicated bars. Bars and error bars show means $\pm \mathrm{SD}$.

Arulampalam, unpublished observations). Because the strongest induction of ANGPTL4 transcription was observed in HT-29 cells, this cell line was chosen to further explore the mechanisms of butyrate-induced expression of this gene. ANGPTL4 expression showed a dose- and time-dependent response to butyrate in HT-29 cells (Fig. 2). These results clearly indicate that ANGPTL4 expression can be induced by butyrate in IEC lines.

Butyrate was also administered to GF mice to ascertain inducibility of ANGPTL4 expression in vivo. Male NMRI GF mice were gavaged with either sterile water or sodium butyrate ( $1 \mathrm{~g} / \mathrm{kg}$ body wt) twice with an 18 -h interval between treatments. Intestinal and colonic epithelial cells were collected $6 \mathrm{~h}$ after the second administration. ANGPLT4 mRNA expression level was higher in epithelial cells from distal small intestine of mice treated with butyrate compared with controls (Fig. 3A). This difference was not observed in the epithelial cells of the colon (Fig. 3B). Together these results show that butyrate is able to induce expression of ANGPTL4 mRNA in IECs both in vitro and in vivo.

Rosiglitazone and butyrate induce ANGPTL4 expression. Butyrate has been postulated to work as a PPAR- $\gamma$ activator (30) or selective modulator (2), and, because HT-29 cells respond to both rosiglitazone and butyrate, we combined these stimuli to gauge for possible additive effects. Together, rosiglitazone and butyrate showed a stronger effect on the expression of ANGPTL4, in all three cell lines tested (Fig. 4, A-C). ANGPTL4 protein secretion was measured in HT-29 cells by ELISA 6 and $24 \mathrm{~h}$ after treatment. At both time points, we have observed elevated levels of this protein in culture medium of cells treated with butyrate. The levels of secreted ANGPTL4 were higher after cotreatment with rosiglitazone and butyrate compared with the stimulation by either one separately (Fig. 4, $D$ and $E$ ). Butyrate was previously shown to transcriptionally activate a wide range of genes involved in the regulation of processes like cell survival, apoptosis, proliferation, and differentiation (15), (17). We therefore tested whether the effect of butyrate alone and in combination with rosiglitazone is specific for ANGPTL4 or could be expanded to other PPAR- $\gamma$ target genes. We monitored the expression of five candidate genes: p21 (a target gene for butyrate but not for PPAR- $\gamma$ ); ADRP, Keratin 20 FABP1 [all previously reported as being PPAR- $\gamma$ target genes in HT-29 (22)], and ANGPTL3 (a gene from the same family as ANGPTL4 but not a PPAR- $\gamma$ target gene). Expression of ADRP and Keratin 20 as well as p21, but not FABP1 or ANGPTL3, was induced by butyrate. Only Keratin 20 showed an additive effect upon cotreatment with rosiglitazone and butyrate (Fig. 5). These results indicate that butyrate is not a universal PPAR- $\gamma$ modulator but rather that the transcriptional outcome of cotreatment of cells with butyrate and rosiglitazone depends on each particular gene.

Butyrate induces ANGPTL4 expression in a PPAR- $\gamma$-independent manner. To investigate a possible interdependence of butyrate-mediated activation and PPAR- $\gamma$, we looked at PPAR- $\gamma$ mRNA and protein levels in HT-29 cells treated with butyrate. The mRNA levels did not change, and, surprisingly, we noted a decrease in PPAR- $\gamma$ protein levels following treatment with butyrate, most prominently at 8 and $24 \mathrm{~h}$ after treatment (Fig. 6, $A$ and $B$ ). We also used the selective PPAR- $\gamma$ inhibitor GW9662 to confirm PPAR- $\gamma$ independence of butyrate action on ANGPTL4 expression in HT-29 cells. As shown in Fig. 6C, ANGPTL4 induction through rosiglitazone is PPAR- $\gamma$ mediated because pretreatment with GW9662 almost completely abolished rosiglitazone-induced ANGPTL4 expression. The stimulatory effect of butyrate, however, is not abolished but did, conversely, increase ANGPTL4 mRNA
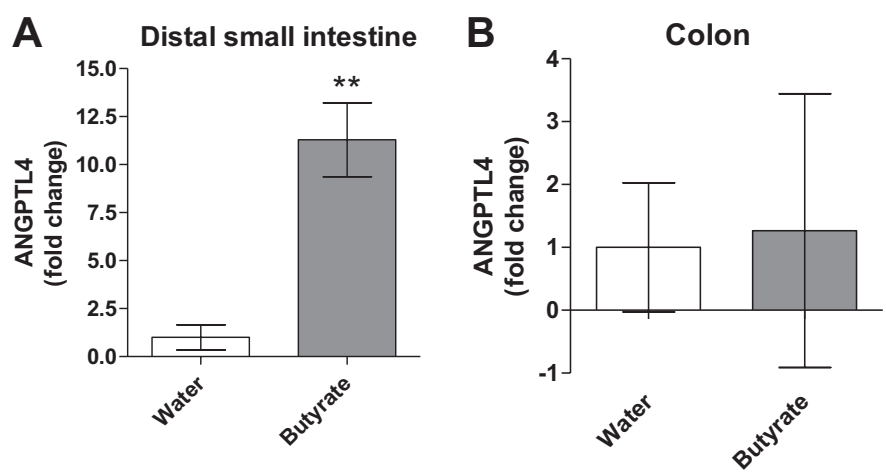

Fig. 3. Sodium butyrate induces expression of ANGPTL4 in mouse intestinal epithelial cells. Quantitative RT-PCR results showing expression of ANGPTL4 in epithelial scrapings from distal small intestine $(A)$ and colon $(B)$ of germ-free mice gavaged with water or sodium butyrate $(1 \mathrm{~g} / \mathrm{kg}$ body wt). Gavage was performed twice for each mouse at 24 and $6 \mathrm{~h}$ before sample collection (4 mice/group). ANGPTL4 expression was normalized to $\beta$-actin. Student's $t$-test, $* * P<0,01$. Bars and error bars show means \pm SEM. 

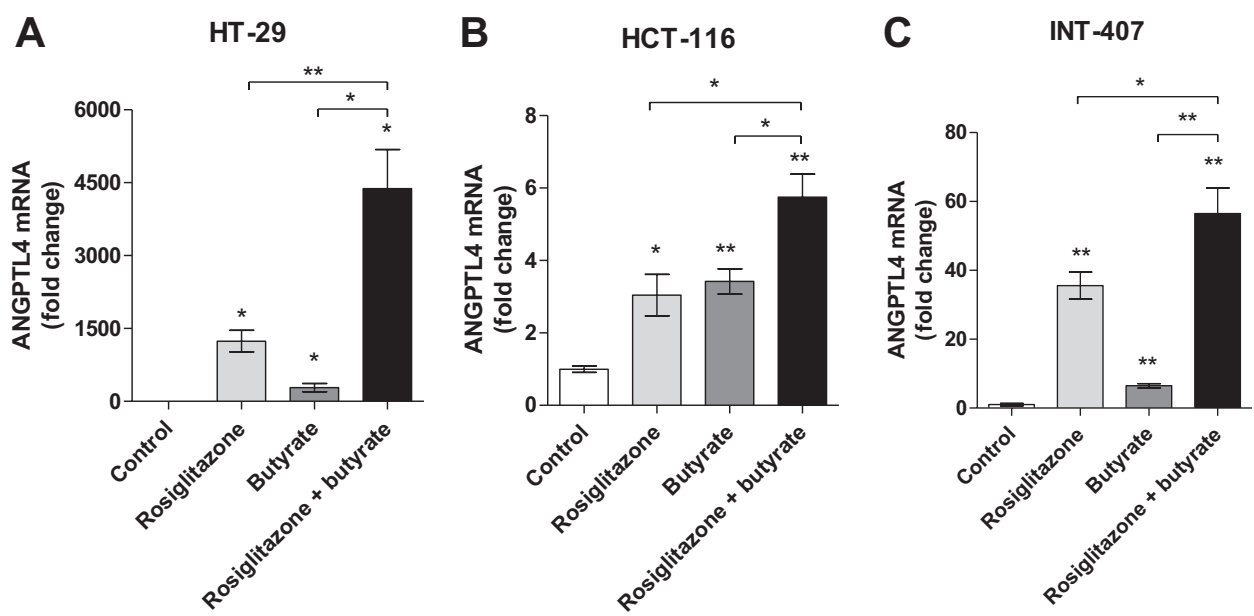

Fig. 4. Cotreatment of HT-29 cells with rosiglitazone and butyrate results in enhanced ANGPTL4 expression. A-C: quantitative RT-PCR results showing combined effects of rosiglitazone and butyrate on ANGPTL4 mRNA in HT-29 (A), HCT-116 (B), or INT-407 (C) cells. Cells were treated for $6 \mathrm{~h}$ with rosiglitazone $(5 \mu \mathrm{M})$, butyrate $(2 \mathrm{mM})$, or a combination of both. The control was treated with $0.025 \%$ DMSO. ANGPTL4 expression was normalized to $\beta$-actin. Student's $t$-test $* P<0.05$; ** $P<$ 0.01 ; *** $P<0.001$ against the control or between indicated bars. Bars and error bars show means \pm SD. $D-E$ : ELISA on culture medium from HT-29 cells treated with butyrate $(2 \mathrm{mM})$, rosiglitazone $(5 \mu \mathrm{M})$, or a combination of both for $6 \mathrm{~h}(D)$ or $24 \mathrm{~h}(E)$. Controls were treated with $0.1 \%$ DMSO. $100 \mu$ l of undiluted supernatant was used per measurement. Student's $t$-test $* P<0.05 ; * * P<0.01 ; * * * P<0.001$ against the control or between indicated bars.
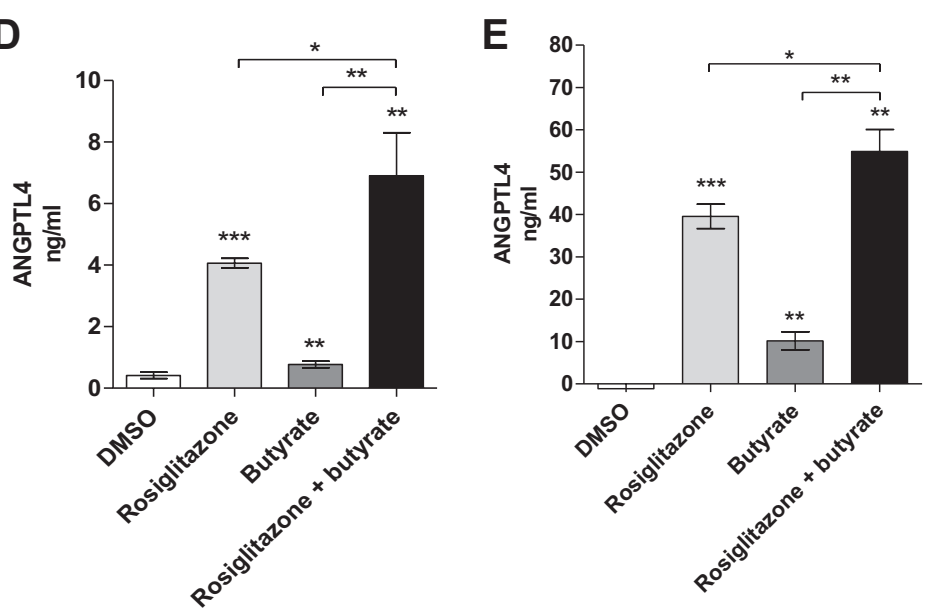

Bars and error bars show means $\pm \mathrm{SD}$.

levels, indicating that butyrate-driven ANGPTL4 expression is PPAR- $\gamma$ independent. The increase in ANGPTL4 expression upon treatment with butyrate in the presence of GW9662 may reflect spurious agonistic activity of GW9662 in the absence of another PPAR activator. The additive effect of rosiglitazone and butyrate appeared to be partially inhibited by GW9662, resulting in the level of ANGPTL4 mRNA seen when cells were cotreated with GW9662 and butyrate alone. To further confirm PPAR- $\gamma$ independence of butyrate effects, we performed siRNA knockdown experiments. Silencing of PPAR- $\gamma$ in HT-29 cells treated with butyrate did not result in blocking of ANGPTL4 expression (Fig. 6D, left), confirming results obtained with the PPAR- $\gamma$ inhibitor in that butyrate effect on ANGPTL4 expression is PPAR- $\gamma$ independent. To ensure that the knockdown was efficient, we treated the HT-29 cells with rosiglitazone and scored for ANGPTL4 mRNA. In this case, the presence of siPPAR- $\gamma$ had an inhibitory effect on rosiglitazone-induced ANGPTL4 expression. We also quantified the expression of PPAR- $\gamma$ for each treatment to ensure that the lack of effect of siPPAR- $\gamma$ in butyrate-treated cells was not due to less efficient knockdown of PPAR- $\gamma$ (Fig. 6D, right).

Together, these results suggest that butyrate- and rosiglitazone-driven expression of ANGPTL4 likely utilizes different pathways and/or distinct transcriptional control elements.

A putative butyrate-responsive element in the ANGPTL4 promoter. To delineate which regulatory elements in the ANGPTL4 gene respond to butyrate, we initiated promoter analysis studies on the ANGPTL4 gene. In silico analysis of the promoter sequence upstream of the transcription start of $A N G$ PTL4 using Genomatix MatInspector software revealed 10 GC-rich sequences, among which 3 were identified as being on the coding strand (hence in accordance with cis-activation as reported for GC-rich boxes), starting at $-362,-1,731$ and $-1,840$, respectively (Table 1 ). Interestingly, two potential PPREs were identified at the positions -982 and $-1,187$ upstream of the transcription start as well. Because we could not exclude a potential implication of PPAR- $\gamma$ in the transcriptional regulation of ANGPTL4 in this region of the promoter, we carried out experiments testing both hypotheses by analyzing three different fragments of the promoter accounting for $1.8,1.2$, and $0.5 \mathrm{~kb}$ upstream of ANGPTL4 transcription start. These three fragments of decreasing sizes were cloned into a luciferase reporter vector (pcDNA3.1-luc) named pANGPTL4-1.8-luc, pANGPTL4-1.2-luc, and pANGPTL4-0.5luc, respectively. The pANGPTL4-0.5-luc and pANGPTL41.8-luc constructs were tested for transcriptional activation by transient transfections in three IEC lines, namely HT-29, HCT116, and SW-1,116 (Fig. 7). All the constructs tested were activated by butyrate; none of them, however, was induced by rosiglitazone, indicating absence of a functional PPRE within the cloned promoter fragment. We further tested whether the induction obtained by butyrate was dependent on the activity of PPAR- $\gamma$ by using the GW9662 inhibitor in SW-1116 cells transiently transfected with the three constructs. We also tested 

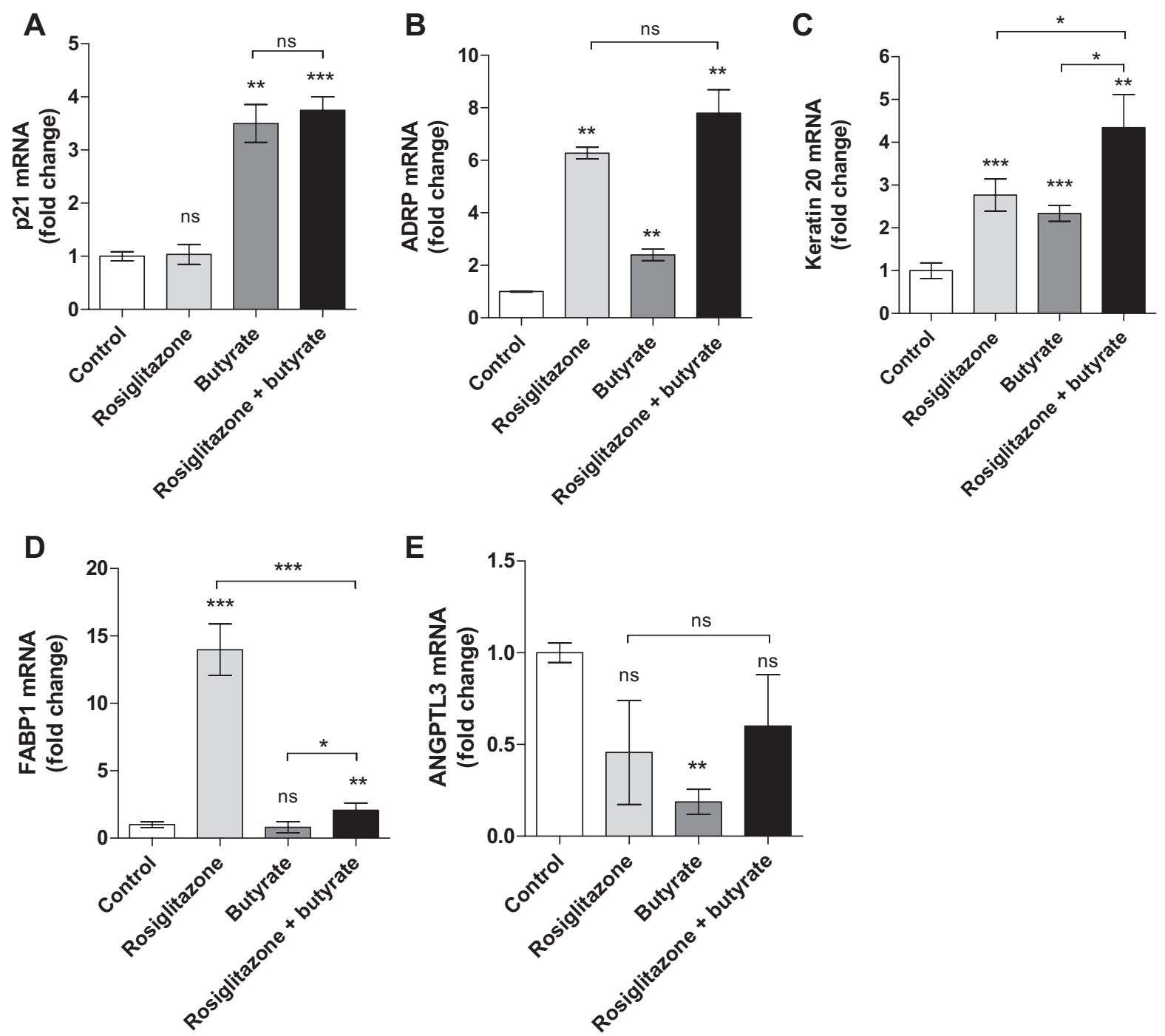

Fig. 5. Expression of p21, adipose differentiation-related protein (ADRP), Keratin 20, but not fatty acid-binding protein gene 1 (FABP1) or ANGPTL3, is induced by butyrate. Quantitative RT-PCR results showing effects of rosiglitazone $(5 \mu \mathrm{M})$, butyrate $(2 \mathrm{mM})$, or a combination of both on p21 (A), ADRP $(B)$, Keratin $20(C)$, FABP1 $(D)$, and ANGPTL3 $(E)$ mRNA in HT-29 cells $6 \mathrm{~h}$ after treatment. The control was treated with 0.025\% DMSO. Levels of p21, ADRP, Keratin 20 , FABP1, and ANGPTL3 expression was normalized to $\beta$-actin. Student's $t$-test ns, $* P>0.05$; $* * P<0.01$; *** $P<0.001$ against the control or between indicated bars. Bars and error bars show means \pm SD.

for a potential additive effect of butyrate when applied together with rosiglitazone. Neither rosiglitazone nor the specific PPAR- $\gamma$ inhibitor GW9662 changed the butyrate-induced upregulation of the reporter gene constructs (Fig. 8). Subsequently, the pANGPTL4-1.8-luc vector was stably transfected into the IEC line SW-1116 (denoted as SWC3 cells) and tested for transcriptional activation. The observations seen in the transient transfections could be confirmed in the stable transfection, whereby butyrate, but not rosiglitazone, was able to induce reporter gene expression (Fig. 9A). This construct was very sensitive to activation with butyrate $(\mathrm{EC} 50=0.56 \mathrm{mM})$ and showed a dose-dependent activation pattern, suggesting a direct effect of butyrate on the promoter region (Fig. 9B).

Induction of ANGPTL4 expression by other SCFA and TSA. Because butyrate is one of the three main SCFA produced through microbial metabolism of dietary fibers, we investigated whether the butyrate-mediated effect could be reproduced by the two other SCFA abundant in the intestine, namely acetate and propionate. Indeed both of these SCFA induced expression of ANGPTL4 mRNA (Fig. 10A) and ANGPTL4 protein secretion (Fig. 10B) in HT-29 cells. To test the specificity on the regulation of the promoter construct, we used a stable reporter cell clone. Acetate was only able to activate the pANGPTL4-1.8-luc promoter reporter when tested at the highest concentration, whereas propionate and butyrate were able to induce reporter gene activity in a dose-dependent manner (Fig. 10C). The additive effect of butyrate and rosiglitazone on ANGPTL4 mRNA expression could also be reproduced, although to a lesser extent, with acetate and propionate (Fig. 10D).

Given that SCFAs can act as histone deacetylase (HDAC) inhibitors $(9,48,51)$, we compared their effects to TSA, a well-known HDAC inhibitor. TSA was able to induce ANGPTL4 mRNA expression (Fig. 10A), protein secretion (Fig. $10 B$ ), and reporter gene activation (Fig. 10C). Moreover the additive effect observed for rosiglitazone and butyrate could 
A

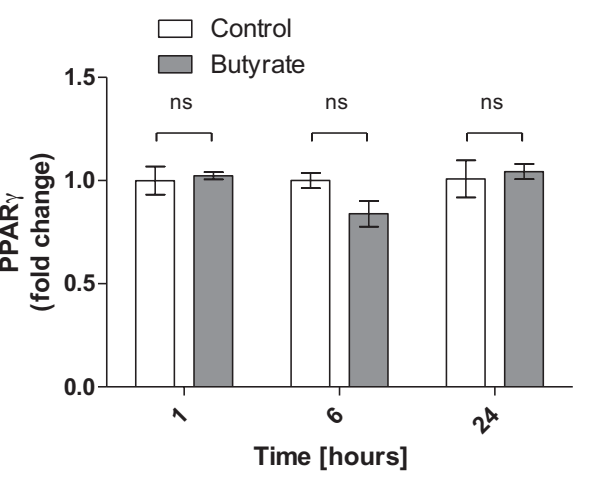

C

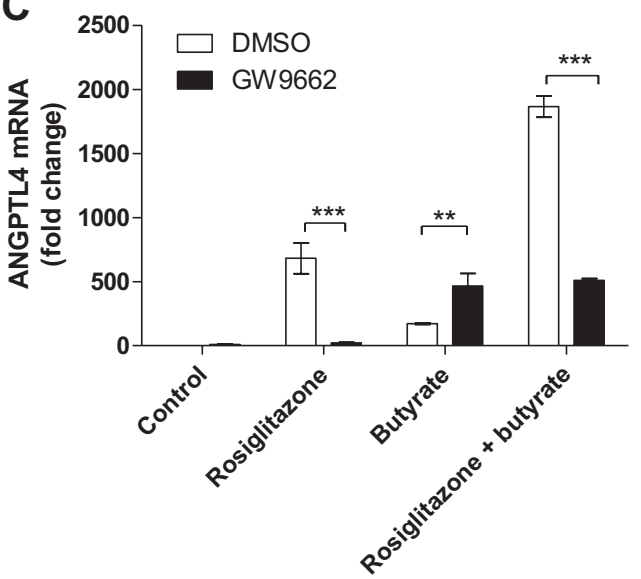

B

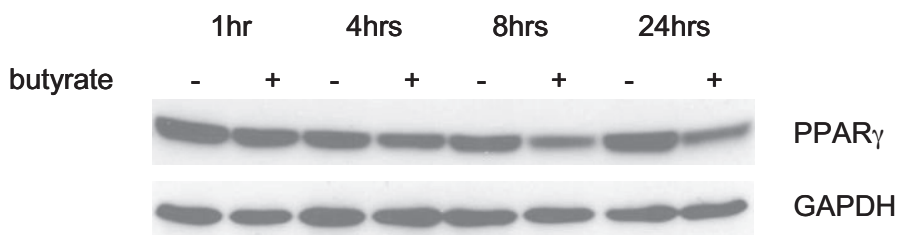

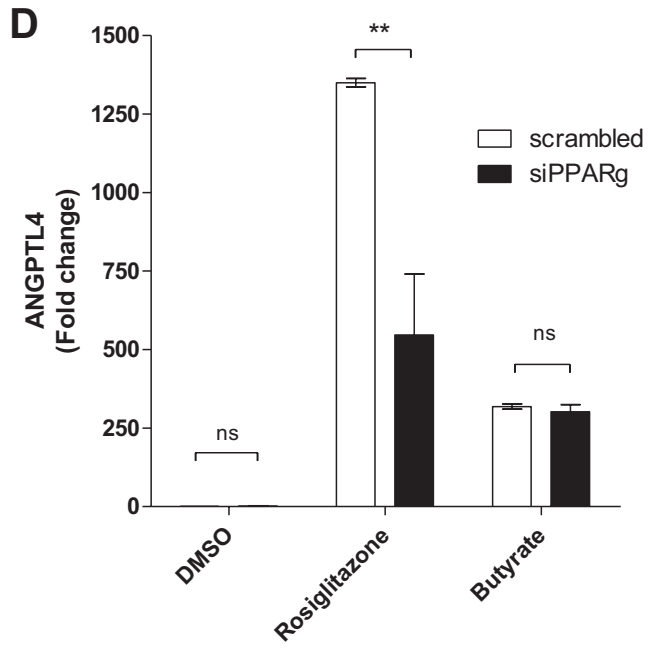

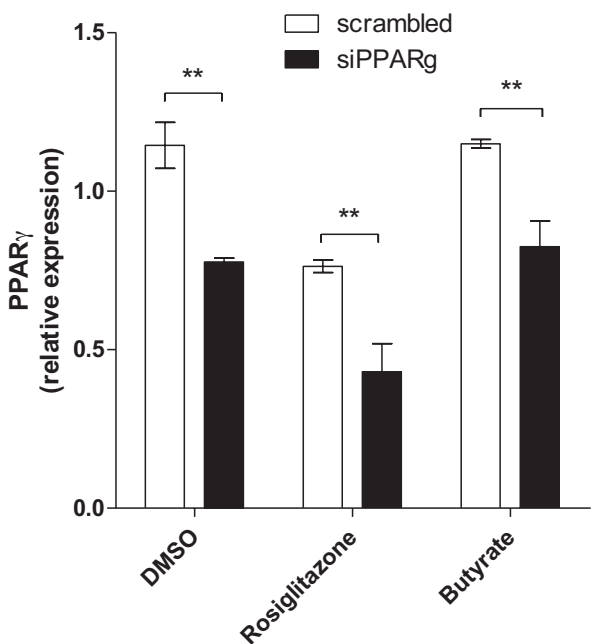

Fig. 6. Butyrate-induced ANGPTL4 expression is peroxisome proliferator-activated receptor (PPAR)- $\gamma$-independent. $A$ : treatment with butyrate does not increase PPAR- $\gamma$ mRNA level. Quantitative RT-PCR results showing PPAR- $\gamma$ expression in HT-29 cells after treatment with butyrate for 1, 6, or 24 h. Controls were treated with culture medium only. PPAR- $\gamma$ expression was normalized to $\beta$-actin. Student's $t$-test ns, $P>0.05$ against between indicated bars. Bars and error bars show means \pm SD. B: treatment with butyrate does not increase PPAR- $\gamma$ protein level. Western blot of whole cell extracts of HT-29 cells stimulated with butyrate $(2 \mathrm{mM})$ for $1,4,8$, or $24 \mathrm{~h}$. Control was treated with culture medium only. GAPDH was used as loading control. $C$ : inhibition of PPAR- $\gamma$ does not block butyrate-induced ANGPTL4 expression. Quantitative RT-PCR results for effects of PPAR- $\gamma$ inhibition on ANGPTL4 mRNA expression in HT-29. Cells were pretreated with GW9662 $(10 \mu \mathrm{M})$ or DMSO $(0.1 \%)$ for $1 \mathrm{~h}$, after which cells were treated with butyrate $(2 \mathrm{mM})$, rosiglitazone $(5 \mu \mathrm{M})$, or a combination of both for $6 \mathrm{~h}$. Control was treated with $0.025 \%$ DMSO. ANGPTL4 expression was normalized to $\beta$-actin. 2 -way ANOVA $* * P<0.01 ; * * * P<0.001$ between indicated bars. Bars and error bars show means \pm SD. $D$ : knockdown of PPAR- $\gamma$ by siRNA does not block butyrate-induced ANGPTL4 expression. Quantitative RT-PCR results showing effects of PPAR- $\gamma$ knockdown by siRNA on ANGPTL4 (left) or PPAR- $\gamma$ (right) mRNA expression in HT-29 cells. Cells were transfected with Silencer Select siRNA products directed against PPAR- $\gamma$ (siPPARg) or Silencer Select Negative Control \#2 siRNA (scrambled). Cells were treated with rosiglitazone $(5 \mu \mathrm{M})$ or butyrate $(2 \mathrm{mM})$ for $6 \mathrm{~h}$. Control was treated with $0.1 \%$ DMSO. ANGPTL4 and PPAR- $\gamma$ expression was normalized to $\beta$-actin. 2-way ANOVA ns, $P>0.05 ; * * P<0.01$, between indicated bars. Bars and error bars show means $\pm \mathrm{SD}$. 

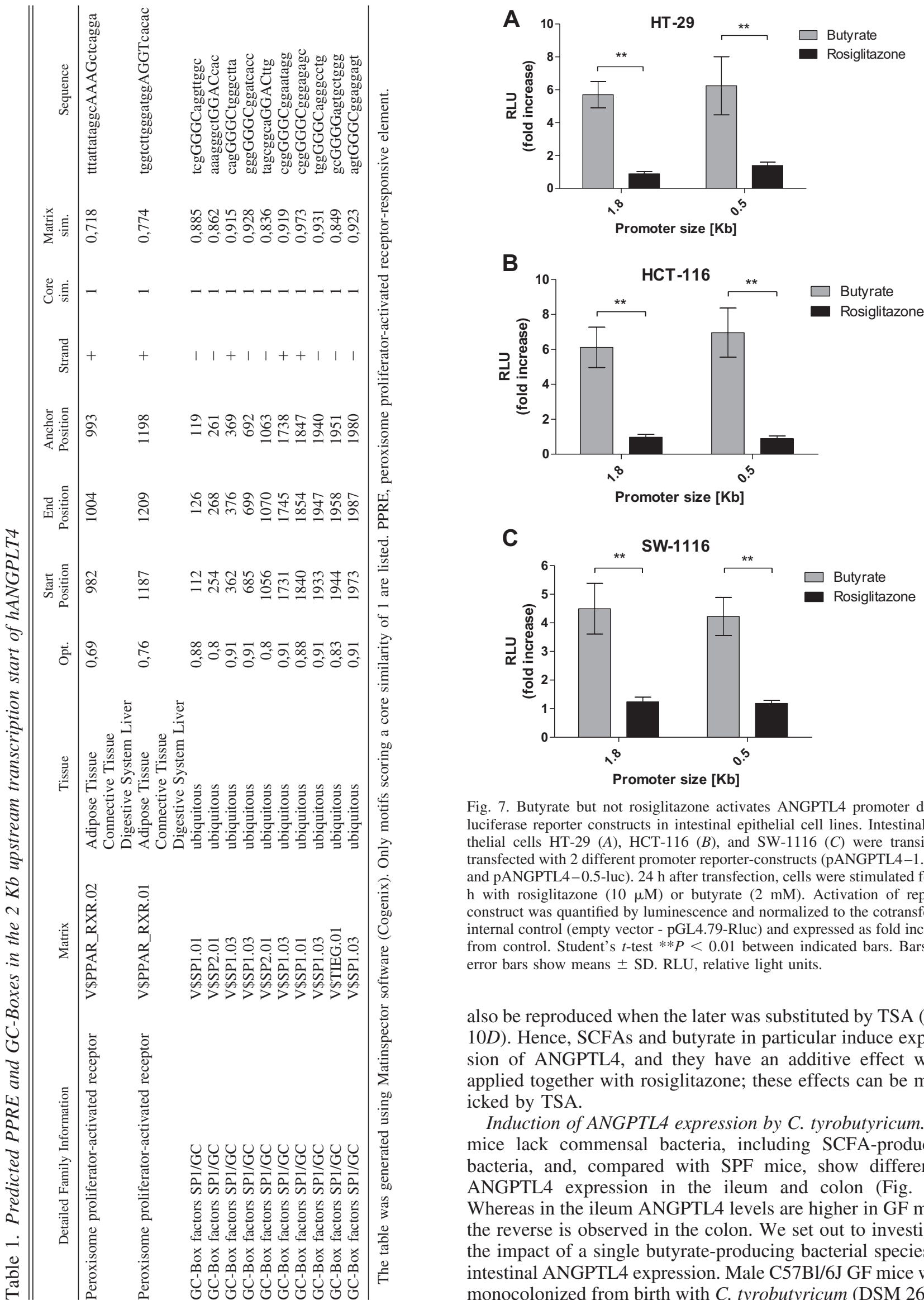

Fig. 7. Butyrate but not rosiglitazone activates ANGPTL4 promoter driven luciferase reporter constructs in intestinal epithelial cell lines. Intestinal epithelial cells HT-29 (A), HCT-116 (B), and SW-1116 (C) were transiently transfected with 2 different promoter reporter-constructs (pANGPTL4-1.8-luc and pANGPTL4-0.5-luc). $24 \mathrm{~h}$ after transfection, cells were stimulated for 24 h with rosiglitazone $(10 \mu \mathrm{M})$ or butyrate $(2 \mathrm{mM})$. Activation of reporter construct was quantified by luminescence and normalized to the cotransfected internal control (empty vector - pGL4.79-Rluc) and expressed as fold increase from control. Student's $t$-test $* * P<0.01$ between indicated bars. Bars and error bars show means \pm SD. RLU, relative light units.

also be reproduced when the later was substituted by TSA (Fig. $10 D)$. Hence, SCFAs and butyrate in particular induce expression of ANGPTL4, and they have an additive effect when applied together with rosiglitazone; these effects can be mimicked by TSA.

Induction of ANGPTL4 expression by C. tyrobutyricum. GF mice lack commensal bacteria, including SCFA-producing bacteria, and, compared with SPF mice, show differential ANGPTL4 expression in the ileum and colon (Fig. 11). Whereas in the ileum ANGPTL4 levels are higher in GF mice, the reverse is observed in the colon. We set out to investigate the impact of a single butyrate-producing bacterial species on intestinal ANGPTL4 expression. Male C57Bl/6J GF mice were monocolonized from birth with C. tyrobutyricum (DSM 2637), 

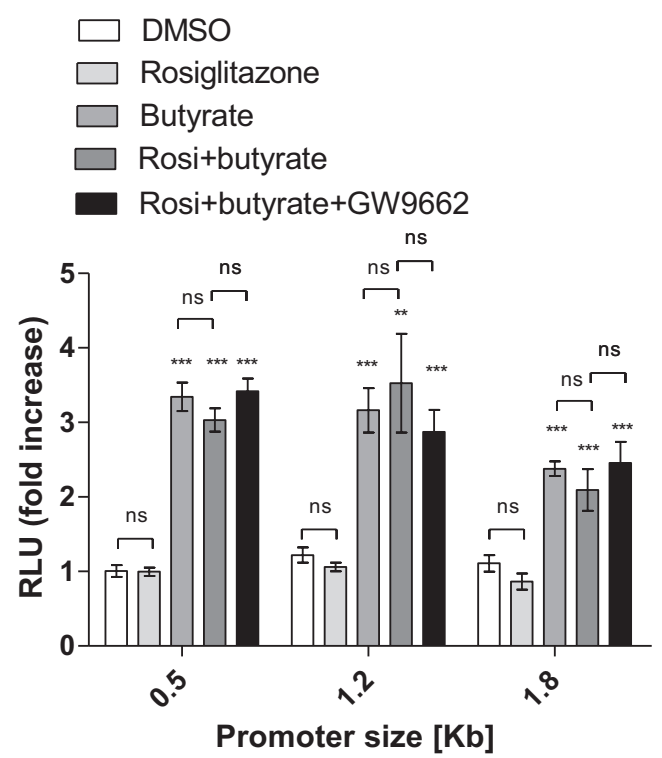

Fig. 8. Butyrate-induced activation of ANGPTL4 promoter-driven luciferase reporter constructs are PPAR- $\gamma$ independent. Cells were transiently transfected with 3 promoter fragments of varying sizes (pANGPTL4-1.8-luc, pANGPTL4-1.2-luc, pANGPTL4-0.5-luc). $24 \mathrm{~h}$ after transfection, cells were stimulated for $24 \mathrm{~h}$ with rosiglitazone $(10 \mu \mathrm{M})$, butyrate $(2 \mathrm{mM})$, and the combination of both in the absence or presence of GW9662 (10 $\mu \mathrm{M})$. Controls were treated with $0.1 \%$ DMSO. Activation of reporter construct was quantified by luminescence and normalized toward the cotransfected internal control (empty vector - pGL4.79-Rluc). Student's $t$-test ns, $P>0.05$; ** $P<0.01$; $* * * P<0.001$ against the control or between indicated bars.

which is able to ferment a wide range of carbohydrates into butyric acid (27). ANGPTL4 expression in the ileum and in colonic epithelial cells was higher in the monoassociated mice compared with the GF mice (Fig. 11), confirming the effect of SCFA-producing bacteria on ANGPTL4 expression.

\section{DISCUSSION}

Here, we show that SCFAs increase ANGPTL4 mRNA and protein expression in IEC lines. In addition, we present data showing for the first time that oral administration of butyrate or colonization of GF mice with butyrate-producing bacteria can increase intestinal ANGPTL4 expression. In the present study, we also set out to ascertain the extent to which butyrate induction of ANGPTL4 expression requires PPAR- $\gamma$ participation.

We and others have previously shown that activation of PPAR $-\gamma$ by its synthetic ligands, as well as by the intestinal microbiota, is linked to increased expression of ANGPTL4 in IECs $(3,4,29)$. In the colon, the abundance of dietary components and microbiota-derived metabolic products may constitute natural ligands for PPAR- $\gamma$. SCFAs and butyrate in particular have been suggested to act as one such activator (30) or selective modulator (2). In this study, we show through the use of the PPAR- $\gamma$ inhibitor GW9662, PPAR- $\gamma$ siRNA knockdown, and luciferase reporter assays that butyrate-induced ANGPTL4 expression in HT-29 cells is PPAR- $\gamma$ independent (Figs. 6, $C$ and $D$, and 8). Despite being PPAR- $\gamma$ independent, costimulation of HT-29 cells with butyrate and rosiglitazone led to increased ANGPTL4 mRNA and protein levels compared with either one treatment alone (Fig. 4, $A, D$, and $E$ ). This presented a means to gauge the universality of butyrate action on PPAR- $\gamma$ target gene expression. Expression of ADRP and Keratin 20 as well as p21, but not FABP1 or ANGPTL3, was induced by butyrate. However, upon cotreatment of cells with rosiglitazone, the PPAR- $\gamma$ target genes (ADRP, Keratin 20, and FABP1) show differential regulation (Fig. 5). This observation allows us to propose that butyrate does not work as a general activator of PPAR- $\gamma$ target gene expression, activating some but not all PPAR- $\gamma$ target genes, and we speculate that this activation may depend on the transcriptional control elements of the individual genes.

Alex and colleagues (2) showed recently that butyrate increased ANGPTL4 expression in a PPAR- $\gamma$-dependent manner in T84 colonic cell line probably by enhancing the binding of PPAR- $\gamma$ to intron 3 of the ANGPTL4 gene. This discrepancy between that study and our data presented in this report may lie in the different IEC lines used, HT-29 vs. T84 cells, different duration of treatment, and, not least important, in the amount of glucose in the respective cell culture media. Furthermore, the ability of butyrate to activate PPAR- $\gamma$ in IEC is concentration
A

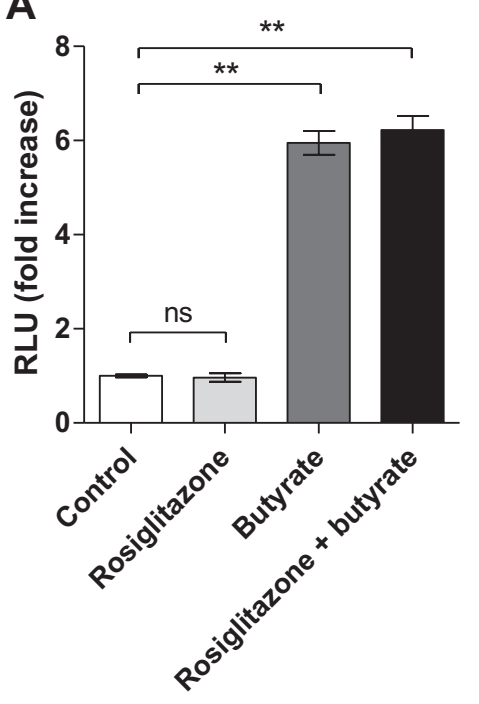

B

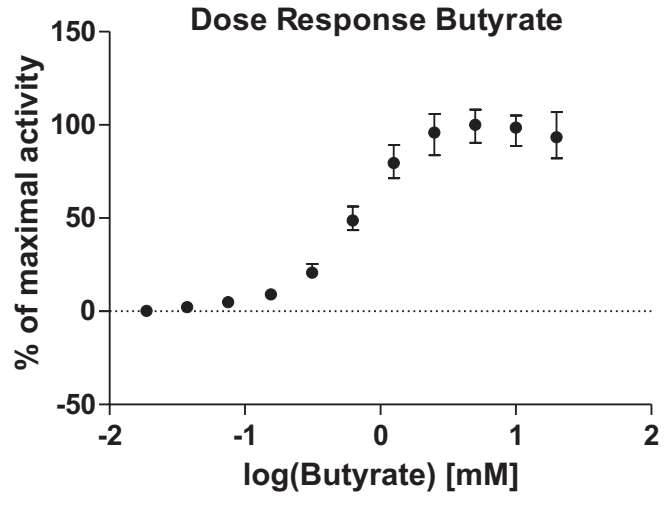

Fig. 9. Butyrate-specific activation of SW-1116 reporter cells stably transfected with a ANGPTL4 promoter-dependent reporter vector. A: stably transfected SW-1116 clone bearing a $1.8 \mathrm{~kb}$ ANGPTL4 promoter luciferase reporter vector was stimulated with rosiglitazone $(10 \mu \mathrm{M})$, butyrate $(2 \mathrm{mM})$, or a combination of both for $24 \mathrm{~h}$. Activation of reporter construct was quantified by luminescence. Student's $t$-test ns, $P>$ 0,05 ; $* * P<0,01$; between indicated bars. Bars and error bars show mean \pm SD. $B$ : dose response of SW-1116 clone 3 cells to butyrate. Results are expressed as \% of the maximum response and are shown as mean \pm SD of 3 separate experiments, each performed in triplicate. 
dependent. PPAR- $\gamma$-independent mechanisms may dominate at higher but physiological SCFA concentrations. Another report has elegantly shown that the action of butyrate on gene transcription, as a function of HDAC inhibition, is dependent on both butyrate concentration and glucose metabolism (17). Because in HT-29 cells the action of butyrate on ANGPTL4 expression was PPAR- $\gamma$ independent, we sought for additional regulatory regions within the ANGPTLA gene that responded to butyrate but not rosiglitazone stimulation. Reporter gene analyses identified elements within ANGPTL4 promoter constructs, stretching from 1.8 to $0.5 \mathrm{~kb}$ upstream of the transcription initiation site, that were activated in the desired manner in HT-29, Caco-2, and SW-1116 cells (Fig. 7). The use of GW9662 did not diminish butyrate inducibility of these constructs in SW-1116 cells (Fig. 8), confirming the absence of a functional PPRE. Hence, rosiglitazone and butyrate seem to act
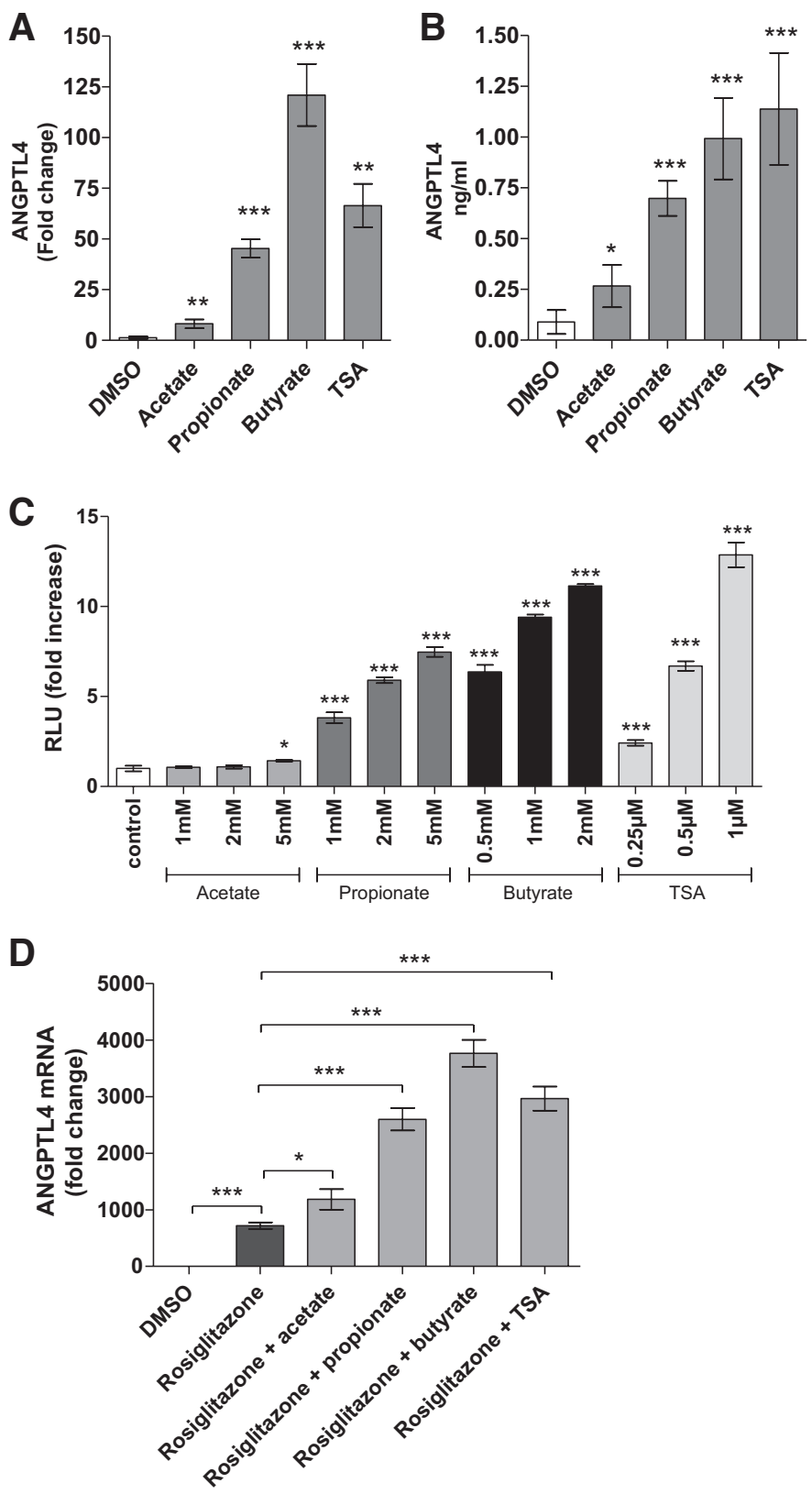

on two separate regulatory sites. We speculate that butyrate alone is sufficient to drive expression of ANGPTL4 through a butyrate-responsive element(s), whereas the addition of rosiglitazone would allow for binding PPAR- $\gamma$ to the PPRE within the third intron of ANGPTL4 gene, resulting in a net increase of ANGPTL4 expression.

One important regulatory mechanism of gene transcription is via acetylation of histones and transcription factors, and SCFAs (especially propionate and butyrate) are potent modulators of protein acetylation. The effect of SCFA on the ANGPTL4 mRNA expression (Fig. 10, $A$ and $D$ ) and protein secretion (Fig. 10B) could be mimicked by TSA, a histone deacetylase inhibitor, structurally and metabolically unrelated to SCFA. The activation of ANGPLT4 promoter constructs by butyrate could also be reproduced by TSA (Fig. 10C). TSA has also been described to modulate the acetylation of Sp1 and subsequently upregulate transcription of transforming growth factor type II receptor gene (26). GC-rich regions of promoter sequences have previously been shown to be activated by butyrate through $\mathrm{Sp} 1$ or $\mathrm{Sp} 3$ binding $(7,13,42)$. Interestingly, one such putative Sp1 binding site was found in the butyrate and TSA-responsive element within the $0.5 \mathrm{~kb}$ fragment of ANGPTL4 promoter (at position -362). Butyrate and TSA could act through regulation of lysine acetylation of transcription factors (including Sp1) and not exclusively as histone deacetylation inhibitors, providing yet another route through which butyrate induces ANGPTL4 transcription in a PPAR- $\gamma$ independent manner.

SCFAs are abundant in the GI tract of conventionally raised mice; GF mice, however, have no microbiota-derived SCFA (25). Here we show that oral administration of butyrate in GF mice results in increased expression of ANGPTL4 in the epithelial cells of the distal small intestine (Fig. 3). This had no effect on the expression of colonic ANGPTL4, possibly due to early absorption and insufficient

Fig. 10. Trichostatin A (TSA) and the short-chain fatty acids (SCFAs) mimic butyrate in the activation of the ANGPTL4 expression in HT-29 cells. A: SCFA or TSA increase expression of ANGPTL4 mRNA in HT-29 cells. Quantitative RT-PCR results for effects of different SCFA and TSA on ANGPTL4 mRNA in HT-29 cells. Cells were stimulated for $6 \mathrm{~h}$ with acetate $(10 \mathrm{mM})$, propionate $(5 \mathrm{mM})$, butyrate $(2 \mathrm{mM})$, or TSA $(500 \mathrm{nM})$. Control was treated with $0.1 \%$ DMSO. ANGPTL4 expression was normalized to $\beta$-actin. Student's $t$-test $* P<0.05 ; * * P<0.01$ against the control. Bars and error bars show means \pm SD. $B$ : SCFA and TSA increase the level of ANGPTL4 protein secreted into the culture medium of HT-29 cells. ELISA on culture medium from HT-29 cells treated with acetate $(10 \mathrm{mM})$, propionate $(5 \mathrm{mM})$, butyrate $(2 \mathrm{mM})$, or TSA $(500 \mathrm{nM})$ for $6 \mathrm{~h}$. Controls were treated with $0.1 \%$ DMSO. $100 \mu l$ of undiluted supernatant was used per measurement. Student's $t$-test $* P<0.05 ; * * * P<0.001$ against the control. Bars and error bars show means \pm SD. $C$ : SCFA and TSA induce luciferase activity in SW-1116 clone 3 reporter cells. Stably transfected SW-1116 clone bearing a $1.8 \mathrm{~kb}$ ANGPTL4 promoter luciferase reporter vector were exposed to different concentrations of acetate, propionate, butyrate, or TSA for $24 \mathrm{~h}$ before measurement of luciferase activity. Student's $t$-test $* P<0.05 ; * * * P<0.001$ against the control. Bars and error bars show means \pm SD. $D$ : cotreatment of HT-29 cells with rosiglitazone and SCFA or TSA results in enhanced ANGPTL4 expression. Quantitative RT-PCR results for combined effects of rosiglitazone and various SCFA on ANGPTL 4 mRNA in HT-29 cells. Cells were treated for $6 \mathrm{~h}$ with rosiglitazone $(5 \mu \mathrm{M})$ alone or in combination with acetate $(10 \mathrm{mM})$, propionate $(5 \mathrm{mM})$, butyrate $(2 \mathrm{mM})$, or TSA $(500 \mathrm{nM})$. Control was treated with DMSO $0.125 \%$. ANGPTL4 expression was normalized to that of $\beta$-actin. Student's $t$-test $* P<$ $0.05 ; * * P<0.01$; *** $P<0.001$ between indicated bars. Bars and error bars show means \pm SD. 
A

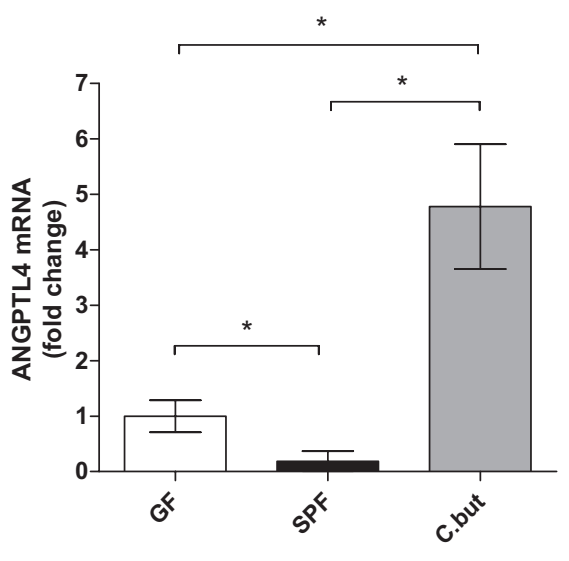

B

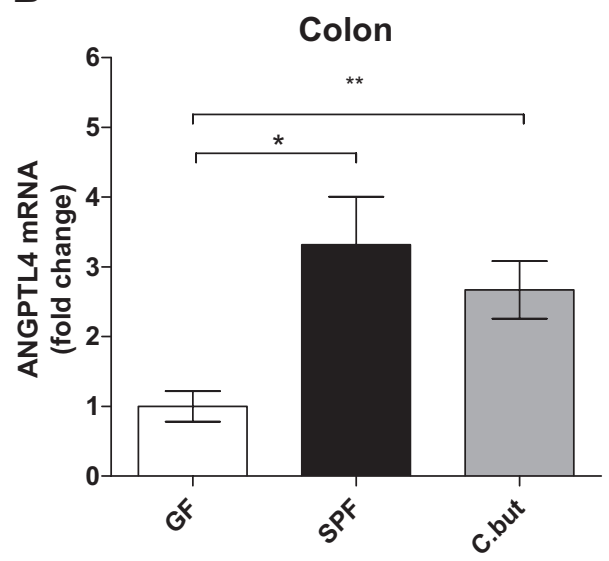

Fig. 11. Colonization of germ-free (GF) mice with Clostridium tyrobutyricum induces expression of ANGPTL4 in the colonic and ileal epithelial cells. Quantitative RT-PCR results for expression of ANGPTL4 in epithelial scrapings from distal small intestine $(A)$ and colon $(B)$ of GF, specific pathogen-free (SPF) and Clostridium tyrobutyricum monoassociated (C. but) mice (5 mice/group). ANGPTL4 expression was normalized to $\beta$-actin. Student's $t$-test $* P<0.05$; $* * P<$ 0.01 between indicated bars. Bars and error bars show means $\pm \mathrm{SE}$. transit to the colon. Intrarectal administration of propionate has been shown to induce expression of colonic ANGPTL4 (2), suggesting that the lack of response from the colonic cells in our experiments is likely due to the route of administration. Synthetic high-fat diet supplemented with butyrate or propionate protects mice from diet-induced weight gain (35), postulating a role of SCFA in the regulation of energy metabolism and weight. We speculate that this effect might be partially mediated by SCFA-driven expression and release of ANGPTL4. Indeed earlier study has suggested that increase in intestinal ANGPTL4 may result in blocking of LPL activity in adipose tissue, therefore preventing fat absorption (5). Our earlier studies have shown that SPF mice fed semisynthetic Western diet $(20 \%$ fat wt/wt) supplemented with a probiotic strain Lactobacillus paracasei ssp paracasei F19 decreased fat storage in these mice. This antiobesogenic effect was attributed to increased ANGPTL4 levels in the plasma of mice that received the probiotic because monoassociation of GF mice with this strain leads to an increase in serum levels of ANGPTL4 (4). In vitro analysis indicated that soluble metabolites originating from $L$. paracasei $\mathrm{F} 19$ are able to increase ANGPTL4 expression in a partially PPAR- $\alpha$ - and PPAR- $\gamma$-dependent manner. Our present data show that SCFA induction of ANGPTL4 expression is PPAR- $\gamma$ independent, thus making it unlikely that these L. paracase $i$ F19-derived metabolites are exclusively SCFAs. It is noteworthy to mention that, in vitro, L. paracasei metabolism results essentially in the production of lactate and acetate, which display poor HDACi activity (37).

A variety of gut bacterial species is able to synthesize SCFAs from dietary fibers (36). Monoassociation of GF mouse with one such butyrate-producing bacteria, Clostridium tyrobutyricum, was able to induce expression of ANGPTL4 in both colonic and ileal epithelial cells (Fig. 11). In the distal small intestine, the levels of epithelial ANGPTL4 mRNA were lower in SPF mice, bearing a broad spectrum of intestinal microbiota, than in GF mice, confirming previous findings $(5,32)$. However, the opposite was observed in the colon with ANGPTL4 mRNA levels higher in SPF than in GF animals. The reason for the contrasting responses is not known but might be related to different bacterial composition in those two compartments, and varying concentrations and proportions of acetate, propionate, and butyrate produced or may reflect differential utilization of these SCFA by the cells. Hence, conventionalization with the whole gut microbiota and the introduction of a single bacterial strain in GF mice appear to have opposite consequences for small intestinal ANGPTL4 expression. Interestingly, C. tyrobutyricum was successfully used to alleviate DSS-induced colitis in mouse models (27). Butyrate-driven ANGPTL4 may therefore participate in the anti-inflammatory effects of SCFAs within the GI tract because SCFAs have been shown previously to protect mice from experimental colitis (49). We speculate that the expression and secretion of intestinal/ colonic ANGPTL4 could have wider tolerogenic and antiinflammatory effects.

In conclusion, we describe here an important role for the SCFA butyrate in the regulation of intestinal ANGPTL4 expression, which may offer a route for SCFAs to regulate the host energy balance and exert anti-inflammatory properties. We also show that PPAR- $\gamma$ is not required for butyrate-driven ANGPTL4 expression. However, PPAR- $\gamma$ ligands together with SCFAs can lead to further increases in ANGPTL4 levels. One of the documented side effects of PPAR- $\gamma$ ligands (e.g., thiazolidinediones, TZDs) used in the treatment of diabetes is weight gain. SCFAs may be used as a supplement in such treatments to minimize the side effect of TZD, i.e., dampening associated weight increase, through ANGPTL4 expression. Finally, oral administration of SCFA or use of SCFA-producing bacteria may be alternative routes to maintain intestinal ANGPTL4 levels.

\section{ACKNOWLEDGMENTS}

We thank Prof Anita Sjölander, Lund University, Lund, Sweden for INT-407 cell line. We also thank Tomas Hudcovic, Helena TlaskalovaHogenova, and Hanna Kozakova from the Department of Immunology and Gnotobiology, Institute of Microbiology, Praha, The Czech Republic, for Clostridium tyrobutyricum.

\section{GRANTS}

This work was supported by the European Community's Seventh Framework Programme (FP7/2007-2013) under grant agreement n²15553-2 (CrossTalk), grant agreement $\mathrm{n}^{\circ} 222720-2$ (TORNADO), grant agreement HEALTHF4-2007-201052 (MetaHIT), as well as from the French National Research Agency (ANR) project MicroObes and the Swedish Research Council. T. de Wouters, A. Korecka, J. Doré, V. Arulampalam, and H. Blottière are members 
of the European Marie-Curie Initial Training Network Cross-Talk (grant agreement no. 215553).

\section{DISCLOSURES}

No conflicts of interest, financial or otherwise, are declared by the authors.

\section{AUTHOR CONTRIBUTIONS}

Author contributions: A.K., T.d.W., and A.C. performed experiments; A.K., T.d.W., N.L., S.P., J.D., H.M.B., and V.A. analyzed data; A.K., T.d.W., S.P., J.D., H.M.B., and V.A. interpreted results of experiments; A.K. and T.d.W. prepared figures; A.K. and T.d.W. drafted manuscript; A.K., T.d.W., H.M.B., and V.A. edited and revised manuscript; A.K., T.d.W., A.C., N.L., S.P., J.D., H.M.B., and V.A. approved final version of manuscript; J.D., H.M.B., and V.A. conception and design of research.

\section{REFERENCES}

1. Adachi M, Kurotani R, Morimura K, Shah Y, Sanford M, Madison BB, Gumucio DL, Marin HE, Peters JM, Young HA, Gonzalez FJ. Peroxisome proliferator activated receptor gamma in colonic epithelial cells protects against experimental inflammatory bowel disease. Gut 55: 1104-1113, 2006.

2. Alex S, Lange K, Amolo T, Grinstead JS, Haakonsson AK, Szalowska E, Koppen A, Mudde K, Haenen D, Al-Lahham S, Roelofsen H, Houtman R, van der Burg B, Mandrup S, Bonvin AM, Kalkhoven E, Muller M, Hooiveld GJ, Kersten S. Short chain fatty acids stimulate Angiopoietin-like 4 synthesis in human colon adenocarcinoma cells by activating PPARgamma. Mol Cell Biol 33: 1303-1316, 2013.

3. Are A, Aronsson L, Wang S, Greicius G, Lee YK, Gustafsson JA, Pettersson S, Arulampalam V. Enterococcus faecalis from newborn babies regulate endogenous PPARgamma activity and IL-10 levels in colonic epithelial cells. Proc Natl Acad Sci USA 105: 1943-1948, 2008.

4. Aronsson L, Huang Y, Parini P, Korach-Andre M, Hakansson J, Gustafsson JA, Pettersson S, Arulampalam V, Rafter J. Decreased fat storage by Lactobacillus paracasei is associated with increased levels of angiopoietin-like 4 protein (ANGPTL4). PloS One 5: e13087, 2010.

5. Backhed F, Ding H, Wang T, Hooper LV, Koh GY, Nagy A, Semenkovich CF, Gordon JI. The gut microbiota as an environmental factor that regulates fat storage. Proc Natl Acad Sci USA 101: 15718-15723, 2004.

6. Backhed F, Manchester JK, Semenkovich CF, Gordon JI. Mechanisms underlying the resistance to diet-induced obesity in germ-free mice. Proc Natl Acad Sci USA 104: 979-984, 2007.

7. Bai L, Merchant JL. Transcription factor ZBP-89 cooperates with histone acetyltransferase p300 during butyrate activation of p21waf1 transcription in human cells. J Biol Chem 275: 30725-30733, 2000.

8. Bercik P, Denou E, Collins J, Jackson W, Lu J, Jury J, Deng Y, Blennerhassett P, Macri J, McCoy KD, Verdu EF, Collins SM. The intestinal microbiota affect central levels of brain-derived neurotropic factor and behavior in mice. Gastroenterology 141: 599-609; e591-593, 2011.

9. Boffa LC, Vidali G, Mann RS, Allfrey VG. Suppression of histone deacetylation in vivo and in vitro by sodium butyrate. J Biol Chem 253: 3364-3366, 1978.

10. Bravo JA, Forsythe P, Chew MV, Escaravage E, Savignac HM, Dinan TG, Bienenstock J, Cryan JF. Ingestion of Lactobacillus strain regulates emotional behavior and central GABA receptor expression in a mouse via the vagus nerve. Proc Natl Acad Sci USA 108: 16050-16055, 2011.

11. Camp JG, Jazwa AL, Trent CM, Rawls JF. Intronic cis-regulatory modules mediate tissue-specific and microbial control of angpt14/fiaf transcription. PLoS Gen 8: e1002585, 2012.

12. Cerf-Bensussan N, Gaboriau-Routhiau V. The immune system and the gut microbiota: friends or foes? Nat Rev 10: 735-744, 2010.

13. Chirakkal H, Leech SH, Brookes KE, Prais AL, Waby JS, Corfe BM. Upregulation of BAK by butyrate in the colon is associated with increased Sp3 binding. Oncogene 25: 7192-7200, 2006.

14. Corfe BM. Hypothesis: butyrate is not an HDAC inhibitor, but a product inhibitor of deacetylation. Mol Biosyst 8: 1609-1612, 2012.

15. Daly K, Shirazi-Beechey SP. Microarray analysis of butyrate regulated genes in colonic epithelial cells. DNA Cell Biol 25: 49-62, 2006.

16. Desai U, Lee EC, Chung K, Gao C, Gay J, Key B, Hansen G, Machajewski D, Platt KA, Sands AT, Schneider M, Van Sligtenhorst I, Suwanichkul A, Vogel P, Wilganowski N, Wingert J, Zambrowicz
BP, Landes G, Powell DR. Lipid-lowering effects of anti-angiopoietinlike 4 antibody recapitulate the lipid phenotype found in angiopoietin-like 4 knockout mice. Proc Natl Acad Sci USA 104: 11766-11771, 2007.

17. Donohoe DR, Collins LB, Wali A, Bigler R, Sun W, Bultman SJ. The warburg effect dictates the mechanism of butyrate-mediated histone acetylation and cell proliferation. Mol Cell 48: 612-626, 2012.

18. Donohoe DR, Garge N, Zhang X, Sun W, O'Connell TM, Bunger MK, Bultman SJ. The microbiome and butyrate regulate energy metabolism and autophagy in the mammalian colon. Cell Metab 13: 517-526, 2011.

19. Fleming SE, Fitch MD, DeVries S, Liu ML, Kight C. Nutrient utilization by cells isolated from rat jejunum, cecum and colon. J Nutr 121: 869-878, 1991.

20. Ge H, Yang G, Huang L, Motola DL, Pourbahrami T, Li C. Oligomerization and regulated proteolytic processing of angiopoietin-like protein 4 . J Biol Chem 279: 2038-2045, 2004.

21. Grootaert C, Van de Wiele T, Verstraete W, Bracke M, Vanhoecke B. Angiopoietin-like protein 4: health effects, modulating agents and structure-function relationships. Expert Rev Proteomics 9: 181-199, 2012.

22. Gupta RA, Brockman JA, Sarraf P, Willson TM, DuBois RN. Target genes of peroxisome proliferator-activated receptor gamma in colorectal cancer cells. J Biol Chem 276: 29681-29687, 2001.

23. Hamer HM, Jonkers D, Venema K, Vanhoutvin S, Troost FJ, Brummer RJ. Review article: the role of butyrate on colonic function. Aliment Pharmacol Ther 27: 104-119, 2008.

24. Heijtz RD, Wang S, Anuar F, Qian Y, Bjorkholm B, Samuelsson A, Hibberd ML, Forssberg H, Pettersson S. Normal gut microbiota modulates brain development and behavior. Proc Natl Acad Sci USA 108: 3047-3052, 2011.

25. Hoverstad T, Midtvedt T. Short-chain fatty acids in germfree mice and rats. J Nutr 116: 1772-1776, 1986.

26. Huang W, Zhao S, Ammanamanchi S, Brattain M, Venkatasubbarao K, Freeman JW. Trichostatin A induces transforming growth factor beta type II receptor promoter activity and acetylation of Sp1 by recruitment of PCAF/p300 to a Sp1 NF-Y complex. J Biol Chem 280: 10047-10054, 2005.

27. Hudcovic T, Kolinska J, Klepetar J, Stepankova R, Rezanka T, Srutkova D, Schwarzer M, Erban V, Du Z, Wells JM, Hrncir T, Tlaskalova-Hogenova H, Kozakova H. Protective effect of Clostridium tyrobutyricum in acute dextran sodium sulphate-induced colitis: differential regulation of tumour necrosis factor-alpha and interleukin-18 in BALB/c and severe combined immunodeficiency mice. Clin Exp Immunol 167: 356-365, 2012.

28. Kaddatz K, Adhikary T, Finkernagel F, Meissner W, Muller-Brusselbach S, Muller R. Transcriptional profiling identifies functional interactions of TGF beta and PPAR beta/delta signaling: synergistic induction of ANGPTL4 transcription. J Biol Chem 285: 29469-29479, 2010.

29. Kersten S, Mandard S, Tan NS, Escher P, Metzger D, Chambon P, Gonzalez FJ, Desvergne B, Wahli W. Characterization of the fastinginduced adipose factor FIAF, a novel peroxisome proliferator-activated receptor target gene. J Biol Chem 275: 28488-28493, 2000.

30. Kinoshita M, Suzuki Y, Saito Y. Butyrate reduces colonic paracellular permeability by enhancing PPARgamma activation. Biochem Biophys Res Commun 293: 827-831, 2002.

31. Korecka A, Arulampalam V. The gut microbiome: scourge, sentinel or spectator? J Oral Microbiol 4: 9367, 2012.

32. Larsson E, Tremaroli V, Lee YS, Koren O, Nookaew I, Fricker A, Nielsen J, Ley RE, Backhed F. Analysis of gut microbial regulation of host gene expression along the length of the gut and regulation of gut microbial ecology through MyD88. Gut 61: 1124-1131, 2011.

33. Lichtenstein L, Berbee JF, van Dijk SJ, van Dijk KW, Bensadoun A, Kema IP, Voshol PJ, Muller M, Rensen PC, Kersten S. Angpt14 upregulates cholesterol synthesis in liver via inhibition of LPL- and HL-dependent hepatic cholesterol uptake. Arterioscler Thromb Vasc Biol 27: 2420-2427, 2007.

34. Lichtenstein L, Mattijssen F, de Wit NJ, Georgiadi A, Hooiveld GJ, van der Meer R, He Y, Qi L, Koster A, Tamsma JT, Tan NS, Muller M, Kersten S. Angpt14 protects against severe proinflammatory effects of saturated fat by inhibiting fatty acid uptake into mesenteric lymph node macrophages. Cell Metab 12: 580-592, 2010.

35. Lin HV, Frassetto A, Kowalik EJ Jr, Nawrocki AR, Lu MM, Kosinski JR, Hubert JA, Szeto D, Yao X, Forrest G, Marsh DJ. Butyrate and propionate protect against diet-induced obesity and regulate gut hormones via free fatty acid receptor 3 -independent mechanisms. PloS One 7: e35240, 2012. 
36. Louis P, Flint HJ. Diversity, metabolism and microbial ecology of butyrate-producing bacteria from the human large intestine. FEMS Microbiol Lett 294: 1-8, 2009.

37. Makras L, Van Acker G, De Vuyst L. Lactobacillus paracasei subsp. paracasei 8700:2 degrades inulin-type fructans exhibiting different degrees of polymerization. Appl Environ Microbiol 71: 6531-6537, 2005

38. Mandard S, Zandbergen F, Tan NS, Escher P, Patsouris D, Koenig W, Kleemann R, Bakker A, Veenman F, Wahli W, Muller M, Kersten S. The direct peroxisome proliferator-activated receptor target fasting-induced adipose factor (FIAF/PGAR/ANGPTL4) is present in blood plasma as a truncated protein that is increased by fenofibrate treatment. $J$ Biol Chem 279: 34411-34420, 2004.

39. Mandard S, Zandbergen F, van Straten E, Wahli W, Kuipers F, Muller M, Kersten S. The fasting-induced adipose factor/angiopoietinlike protein 4 is physically associated with lipoproteins and governs plasma lipid levels and adiposity. J Biol Chem 281: 934-944, 2006.

40. Mohapatra SK, Guri AJ, Climent M, Vives C, Carbo A, Horne WT, Hontecillas R, Bassaganya-Riera J. Immunoregulatory actions of epithelial cell PPAR gamma at the colonic mucosa of mice with experimental inflammatory bowel disease. PloS One 5: e10215, 2010.

41. Musso G, Gambino R, Cassader M. Interactions between gut microbiota and host metabolism predisposing to obesity and diabetes. Anпи Rev Med 62: 361-380, 2011.

42. Nakano K, Mizuno T, Sowa Y, Orita T, Yoshino T, Okuyama Y, Fujita T, Ohtani-Fujita N, Matsukawa Y, Tokino T, Yamagishi H, Oka T, Nomura H, Sakai T. Butyrate activates the WAF1/Cip1 gene promoter through $\mathrm{Sp} 1$ sites in a p53-negative human colon cancer cell line. J Biol Chem 272: 22199-22206, 1997.

43. Petersson J, Schreiber O, Hansson GC, Gendler SJ, Velcich A, Lundberg JO, Roos S, Holm L, Phillipson M. Importance and regulation of the colonic mucus barrier in a mouse model of colitis. Am J Physiol Gastrointest Liver Physiol 300: G327-G333, 2011.

44. Robciuc MR, Naukkarinen J, Ortega-Alonso A, Tyynismaa H, Raivio T, Rissanen A, Kaprio J, Ehnholm C, Jauhiainen M, Pietilainen KH. Serum angiopoietin-like 4 protein levels and expression in adipose tissue are inversely correlated with obesity in monozygotic twins. J Lipid Res 52: 1575-1582, 2011.

45. Roediger WE. Utilization of nutrients by isolated epithelial cells of the rat colon. Gastroenterology 83: 424-429, 1982.

46. Schallehn G, Wolff MH. [Morphological changes in human embryonic lung fibroblasts caused by cytotoxins of various Clostridium species]. Zentralbl Bakteriol Mikrobiol Hyg A 267: 367-378, 1988.

47. Scheppach W, Weiler F. The butyrate story: old wine in new bottles? Curr Opin Clin Nutr Metab Care 7: 563-567, 2004

48. Sealy L, Chalkley R. The effect of sodium butyrate on histone modification. Cell 14: 115-121, 1978.

49. Segain JP, Raingeard de la Bletiere D, Bourreille A, Leray V, Gervois N, Rosales C, Ferrier L, Bonnet C, Blottiere HM, Galmiche JP. Butyrate inhibits inflammatory responses through NFkappaB inhibition: implications for Crohn's disease. Gut 47: 397-403, 2000.

50. Sekirov I, Russell SL, Antunes LC, Finlay BB. Gut microbiota in health and disease. Physiol Rev 90: 859-904, 2010.

51. Siavoshian S, Segain JP, Kornprobst M, Bonnet C, Cherbut C, Galmiche JP, Blottiere HM. Butyrate and trichostatin A effects on the proliferation/differentiation of human intestinal epithelial cells: induction of cyclin D3 and p21 expression. Gut 46: 507-514, 2000.

52. Topping DL, Clifton PM. Short-chain fatty acids and human colonic function: roles of resistant starch and nonstarch polysaccharides. Physiol Rev 81: 1031-1064, 2001.

53. Ulluwishewa D, Anderson RC, McNabb WC, Moughan PJ, Wells JM, Roy NC. Regulation of tight junction permeability by intestinal bacteria and dietary components. J Nutr 141: 769-776, 2011.

54. Wahli W. A gut feeling of the PXR, PPAR and NF-kappaB connection. J Intern Med 263: 613-619, 2008.

55. Xu A, Lam MC, Chan KW, Wang Y, Zhang J, Hoo RL, Xu JY, Chen B, Chow WS, Tso AW, Lam KS. Angiopoietin-like protein 4 decreases blood glucose and improves glucose tolerance but induces hyperlipidemia and hepatic steatosis in mice. Proc Natl Acad Sci USA 102: 6086-6091, 2005 . 